\title{
Chapter 17 \\ Development of Ultrafast X-ray Free \\ Electron Laser Tools in (Bio)Chemical \\ Research
}

\author{
Simone Techert, Sreevidya Thekku Veedu and Sadia Bari
}

\begin{abstract}
The chapter will focus on fundamental aspects and methodological challenges of X-ray free electron laser research and recent developments in the related field of ultrafast X-ray science. Selected examples proving "molecular movie capabilities" of Free-electron laser radiation investigating gas phase chemistry, chemistry in liquids and transformations in the solid state will be introduced. They will be discussed in the context of ultrafast X-ray studies of complex biochemical research, and time-resolved X-ray characterisation of energy storage materials and energy bionics.
\end{abstract}

\subsection{Introduction}

After a preparation phase of almost twenty years-from the first vision of a common research effort in synchrotron radiation in Europe (1975) up to the first electron beam entering the first high-brilliant, third generation X-ray synchrotron ring in 1992 (at the European Synchrotron Radiation Facility)—synchrotron radiation has proven its unique X-ray photons characteristics in brilliance, coherence, pulsed properties and high-repetition frequencies - allowing for the development of various synchrotrontypical experiments such as high-resolution X-ray crystallography and anomalous $\mathrm{X}$-ray scattering, the various types of X-ray spectroscopy techniques, X-ray timeresolved methods and coherent and incoherent X-ray diffraction techniques (to name some examples). The techniques have been adapted for and applied to material research, chemistry, solid state and biophysics, earth and planetary research, astrophysics etc.

S. Techert $(\bowtie) \cdot$ S. Thekku Veedu $\cdot$ S. Bari

FS-Strukturdynamik (bio)chemischer Systeme, Deutsches Elektronen-Synchrotron DESY,

Notkestraße 85, 22607 Hamburg, Germany

e-mail: simone.techert@desy.de

T. Salditt et al. (eds.), Nanoscale Photonic Imaging, Topics in Applied Physics 134, https://doi.org/10.1007/978-3-030-34413-9_17 
In the begin of the 2nd millennium, synchrotron researchers faced a similar situation as in begin of 1980s — again with a 20 years agenda from 2000 on-entering their next research "quantum step" by extending the novel technique of the so-called Free-Electron Laser (FEL) principle [1-6] from short arrangements of water-cooled magnets to very long arrangements of water-cooled (and now even superconducting) magnets [1-6]. Since in free-electron lasers high-speed electrons freely move in a magnetic field [1, 2], being accelerated and decelerated in the field, and by thus generating radiation, changing the properties of the magnetic fields as explained allow for moving from the FEL-generation of micro-waves $[2,4]$ to the ones of X-ray radiation [4-6]. Free-electron lasers are therefore fully tunable and they have the widest frequency range of any laser type.

By developing the FEL-principle to the hard X-ray regime [4-7]—a gap between the "traditional" synchrotron radiation world and the FEL radiation world has been closed-one of the reasons why FEL radiation is also sometimes called "synchrotrons of the 4th generation" (at least from the perspective of synchrotron researchers). As a consequence, the properties of the novel FEL sources and the properties of the produced X-ray radiation have been amplified by many orders of magnitudes compared to current synchrotron sources of the 3rd generation.

Milestones in the FEL development agenda were the first soft X-ray free-electron laser in operation-2005 the Free-Electron LASer FLASH at DESY in Hamburg, the first hard X-ray free-electron laser in operation-2009 the Linear Coherent Light Source LCLS at SLAC in Stanford (which is a so-called 1st generation of FELs based on a low-repetition frequency approach), and the first high-repetition frequency hard X-ray FEL in operation-2017 the European X-ray Free Electron Laser European XFEL at DESY and in Schenefeld. How these "quantum jumps" in X-ray properties can be made used for novel approaches of research in chemistry will be topic of this chapter.

In order to reflect milestones developments from 2006 on, the chapter reflects recent research summaries [8-10] as well as novel developments.

If one reads about chemical reactions and the measurement of real-time responses in chemical reactions, one very quickly ends up with the concept of the resolution of measurements on ultrafast time scales, which are characteristic for the movement of atoms in molecules, i.e. femtoseconds. A femtosecond is defined as the millionth of a billionth of a second. Life-relevant motions, however, can be as slow as seconds or even up to minutes' or hours' time scales. The origin of these time scale differences is based on the complexity of the coordination space of a proceeding reaction [8-14].

In a classical kinetic scheme, following the explanatory approach, the gradients on the potential energy hypersurface define the molecular dynamics. Statistically population-weighted, they compose to the kinetics of a chemical reaction. The coordinates describing the dynamics and kinetics of a chemical reaction are the reaction coordinate and the energy. The reaction coordinate is defined as a one-dimensional projection of the reactant's and product's normal coordinates, which span the potential energy hypersurface of reactant and product and the potential energy hypersurfaces of their transitions (Fig. 17.1). The energy gradient along a reaction coordinate 


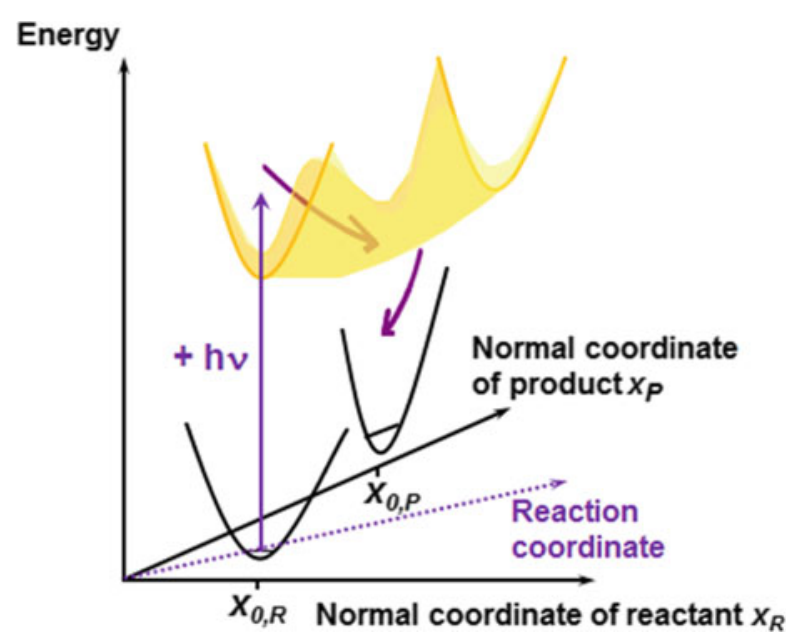

Fig. 17.1 References [11-16]: Potential energy hyper-surface of a chemical reaction. The reaction coordinate (abscissa) of a chemical reaction is defined as a one-dimensional projection of the normal coordinates spanning the reactant's potential energy hypersurface versus the normal coordinates spanning the product's potential energy hypersurface, and their corresponding transitions [11, 14]. The figure is adapted from the [8-10] and references therein

is defined as reaction dynamics, the energy gradient along the normal coordinates as molecular dynamics.

Commonly, the potential energy is presented as the characteristic curve or hypersurface in the graph, and the ordinate axis presents the sum of the potential and kinetic energy of the nuclei involved in the chemical reaction (Fig. 17.2). Potential and kinetic energy of molecules can be detangled through the projection of the potential energy onto the total energy axis. The activated complex and transition state (according to Eyring) includes an imaginary vibrational mode [11-14, 16].

From a chemical physicist's point of view, one would like to understand which elementary chemical processes happen at which time scales, and how these time scales are inter-connected. To what extend do structural motifs "freeze in" time and dynamics information of chemical reactions? Which type of apparatus needs to be built and which kind of methods need to be developed for investigating the created femtosecond "time stamps" in the structure of complex matter during a chemical or biochemical reaction?

Ultrafast X-ray methods bear the potential of determining the complexity of chemical reactions-during their reactions, in particular in the bulk, with techniques which utilize the specific characteristics of X-ray/matter interaction: in wellordered systems, $\mathrm{X}$-ray crystallography as a Thomson scattering process allows for element-specific determinations such as electron densities (redox states) and highprecision spatial resolution determination of atoms in lattices from which hydrogen bonding, chemical bonding or van der Waals stacks can be derived. In less-ordered and disordered systems, X-rays deliver element-specific information of the investi- 


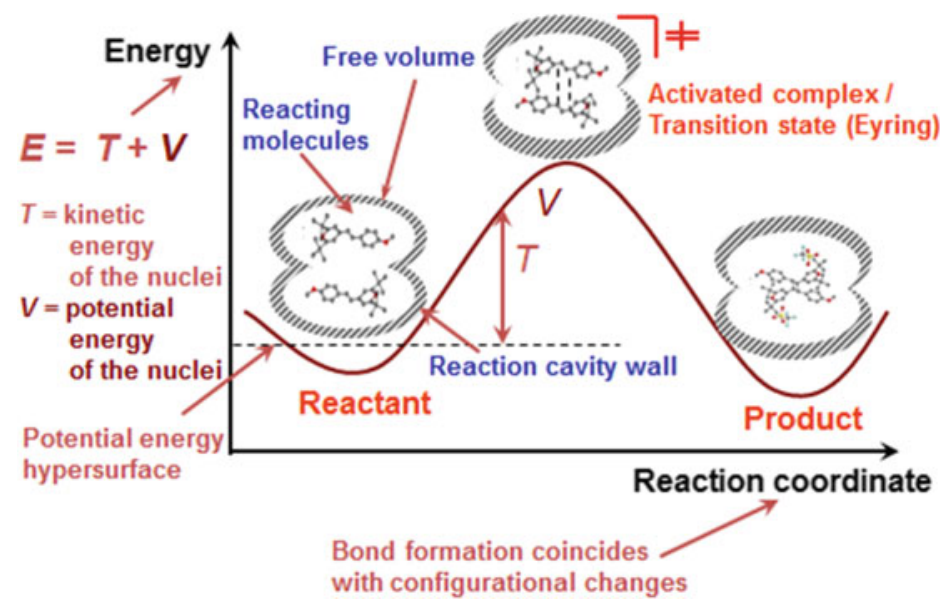

Fig. 17.2 References [11-16]: Total energy of a chemical system as the sum of potential energy (V) and kinetic energy ( $\mathrm{T}$ ) of the molecules (ordinate). Inside the graph, only the contribution of the potential energy is plotted; its projection onto the ordinate allows determining the kinetic energy $[12,16]$. The figure is adapted from the $[8-10]$ and references therein

gated molecules utilizing, for example, X-ray spectroscopy, X-ray absorption, photoinduced electron cascades, or X-ray and electron emission properties. Site-specific information is obtained by elastic and inelastic scattering processes such as multidimensional X-ray spectroscopy, X-ray diffraction, or X-ray scattering. The chemical consequences of X-ray/matter interactions leading to fragmentation can be characterized by X-ray mass spectrometry.

Characteristic for the X-ray photons generated in synchrotrons and free-electron lasers are their

1. energy tunability (allowing for excitation-energy-sensitive methods like X-ray spectroscopy or advanced X-ray diffraction methods)

2. pulsed structure (allowing for in-situ and time-resolved X-ray methods)

3. defined polarization (allowing for advances in X-ray spectroscopy)

4. coherence (allowing for X-ray imaging or correlation spectroscopy methods)

5. high flux (allowing for high-resolution X-ray experiments in all experimental domains)

Fourth generation accelerator-based light sources (free-electron lasers, FELs) in the VUV or X-ray regime deliver ultra-brilliant coherent radiation in very short pulses ( $10^{12}$ to $10^{13}$ photons/bunch/10-100 fs). In order to fully exploit their unique photon capabilities, novel instrumentation is required based on single-shot (collection) schemes. Moreover, hundreds up to trillions of fragment particles, ions, electrons or scattered photons can emerge when a single light flash impinges on matter with intensities up to (predicted for the XFEL) $10^{22} \mathrm{~W} \mathrm{~cm}^{-2}$. In order to meet these challenges, in the starting time of FLASH (Free-Electron Laser in Hamburg [16a]) and 
the LCLS (Linac Coherent Light Source [16b]), various experimental chambers and endstations have been designed. Further constructions, in particular for relevance for this chapter have been developed and are under construction at the European XFEL [16e], as shortly been explained in the following.

Starting from this introduction as a comprehensive summary of the basic principles, in the following, various FEL methods developed so far will be summarised, including the concept of filming chemical reactions in real time utilizing ultrafast high-flux X-ray sources [11-16], X-ray Diffraction and Crystallography for Condensed State Chemistry Studies-Crystallography with Ultrahigh Temporal and Ultrahigh Spatial Resolution [14, 17-52] and Applications in organic electronics and energy research [14, 53-59]; from From Local to Global: Ultrafast Multidimensional Soft X-ray Spectroscopy and Ultrafast X-ray Diffraction Shake Their Hands [60-76] and Applications in Bimolecular Reaction Studies and Photocatalysis [7780] to Applications in Unimolecular Liquid Phase Reaction Dynamics [81-89] and Applications in Bioelectronics, Aqueous and Prebiotics Reaction Dynamics [90-108] to Applications in Biophysics and Gas Phase Biomolecules [109-121]; from Ultrafast Imaging of Gas Phase Reactions [122-127] and Applications in Nanoscience and Multiphoton-Ionisations [128-150] to Applications in Unimolecular Gas Phase Dynamics [122, 151-163] and Outlook.

\subsection{The Concept: Filming Chemical Reactions in Real Time Utilizing Ultrafast High-Flux X-ray Sources}

In a proof-of-principle experiment at the white beam beamline at the ESRF (The European Synchrotron Research Facility) in 2001, it has been demonstrated that high-flux, pulsed X-rays - as created with synchrotrons of the 3rd generation-can act as the "photons of choice" for studying the dynamics and kinetics of small chemical systems on their complex reaction landscape [1]. These studies have been used to define various expectation values for time-resolved experiments at free-electron lasers and saddling the ground for ultrafast X-ray experiments at these sources. Since then, also the phrase of recording the molecular movie has been born (Fig. 17.3) [2-6b].

Figure 17.3 summarizes the principles of such a "molecular movie" approach: after the initialization of a chemical reaction with a short laser pulse, ultrafast X-ray FEL snapshots take photographs of the X-ray spectroscopic or X-ray diffraction signal. By varying the time delay between laser pump and X-ray probe pulse, information about the structural changes as a function of time are collected.

Time-wise, the criterion for "recording the molecular movie" is given when the time resolution of the pump and probe sources meet the time scales of the structural dynamics investigated. The resolution criterion for structural dynamics studies is fulfilled in chemistry, when the refined structure allows for determining the electron 


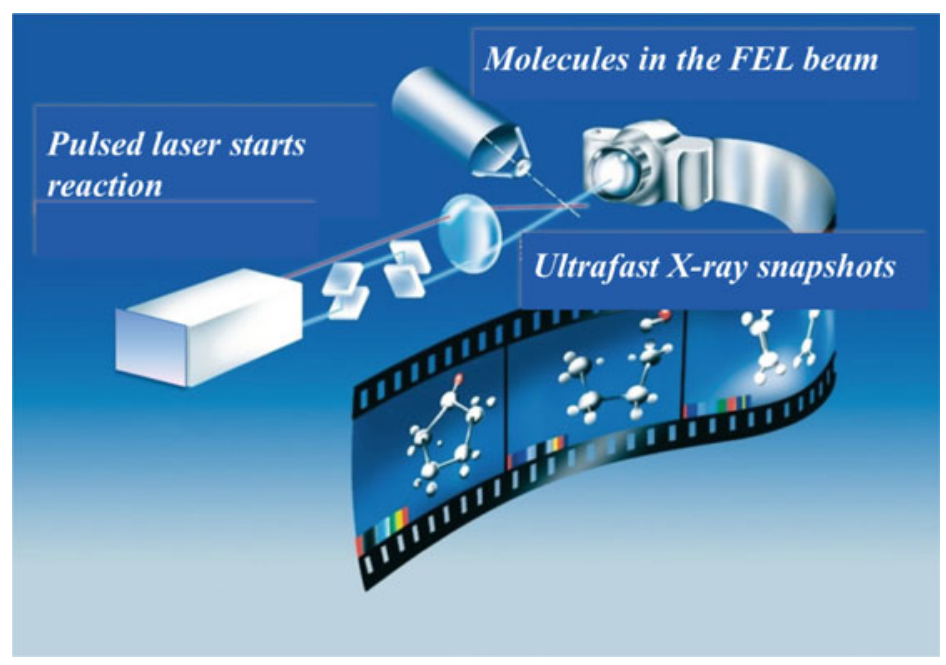

Fig. 17.3 References [11-16]: Principle of the "molecular movie". After the initialization of a chemical reaction by a pulsed trigger laser, ultrafast X-ray snapshots and photographs of the X-ray pulses are collected as a function of time (courtesy by DESY, MPIbpC and European XFEL)

density or the charge densities (which are equal in the redox state) around a moving atom. High-resolution X-ray crystallography studies contains such precision [2, 8$16,21,23,25,35,44,46,51]$.

\subsection{X-ray Diffraction and Crystallography for Condensed State Chemistry Studies-Crystallography with Ultrahigh Temporal and Ultrahigh Spatial Resolution}

Crystallography with ultrahigh temporal and spatial resolution allows studying photochemical reactions beyond conventional quantum chemical approaches. Far beyond any present laboratory technique, time-resolved synchrotron (picosecond time resolution) and FEL (femtosecond time resolution) experiments emphasize the uniqueness of the pulsed, ultrafast, high brilliant and coherent X-ray methods and metrology. For chemical bond breaking and bond formation, the criterion for spatial resolution is met in periodic systems (crystallography) when $0.01-0.001 \AA$ resolution diffractograms yield high precision structural information $[8-16,21-23,25,35,44,46$, 51].

Figure 17.4 reflects the changes of X-ray synchrotron beam characteristics when evolving from synchrotrons of the 2 nd generation towards hard X-ray free electron lasers. The diffractograms have been collected on a molecular crystal of the same species, the same crystal quality and the same orientation. Utilizing broadband 
Average Brilliance / ph/(sec $\mathrm{mrad}^{2} \mathrm{~mm}^{2} 0.1 \%$ bw)

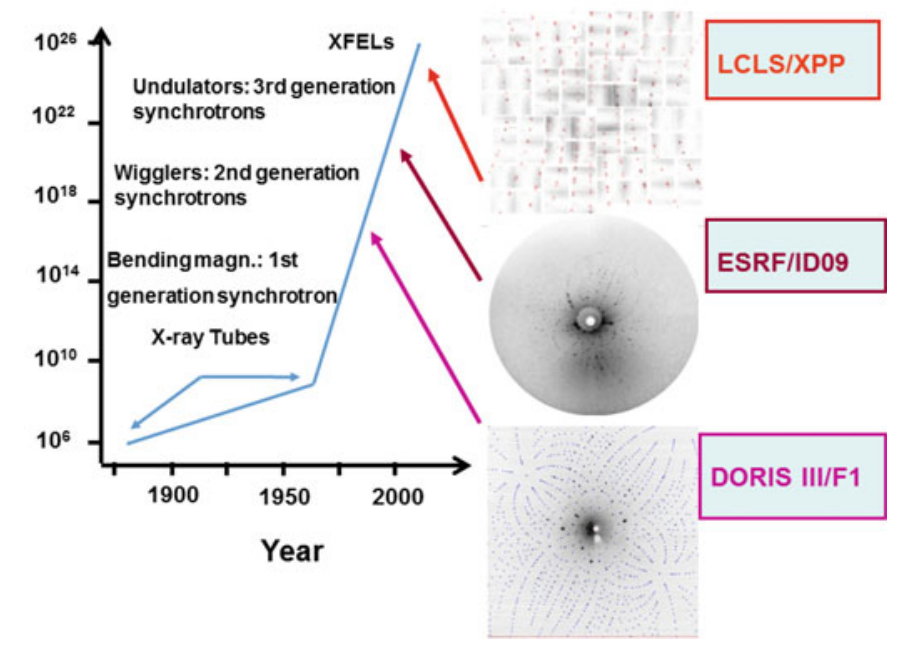

Fig. 17.4 References [17-52]: Evolution of the average brilliance of synchrotron radiation light of synchrotrons of the 2nd generation (DORIS) though the ESRF towards LCLS free-electron lasercharacterized at the high-resolution diffraction pattern of the same molecular crystal system with same crystal quality (courtesy by DESY, ESRF and LCLS). The figure is adapted from the [8-10] and references therein

wiggler radiation in 2nd generation synchrotrons (F1/DORIS) Laue diffraction pattern have been collected. Taped undulator radiation of synchrotrons of the 3rd generation yields in quasi Pink-Laue diffractograms (ID09/ESRF).

Compared to the Pink Laue white beam at XPP as well as CXI beamline of LCLS, the FEL radiation is about one to two orders of magnitude smaller in bandwidth, allowing only the investigation of a statistical number of Bragg reflections for small molecular crystals when the crystal is rotated.

Small molecular crystallography at free-electron lasers could be quantitatively utilized for structure determination by the combination of traditional Laue crystallography and FEL- specific serial crystallography techniques with rapid sample exchange and based on a single shot data collection strategy analogous to the developments of time-resolved Laue diffraction at synchrotrons of the 3rd generation.

In contrast to conventional Laue crystallography, for normalization purposes during FEL experiments, every diffractogram needs to be associated to an online collected X-ray spectrum. Utilizing high X-ray energies well above $15 \mathrm{keV}$ (use of the third harmonic and smaller X-ray/atom cross section) with no monochromatization in pink Laue modus reduces radiation damage so that with a monotonically running spindle and randomly changing X-ray wavelength with known X-ray spectral characteristics, various orientations under defined $\mathrm{X}$-ray conditions can be collected. They are sufficient for determining the orientation matrix of small molecules and hence following the indexing of the collected diffractograms. 


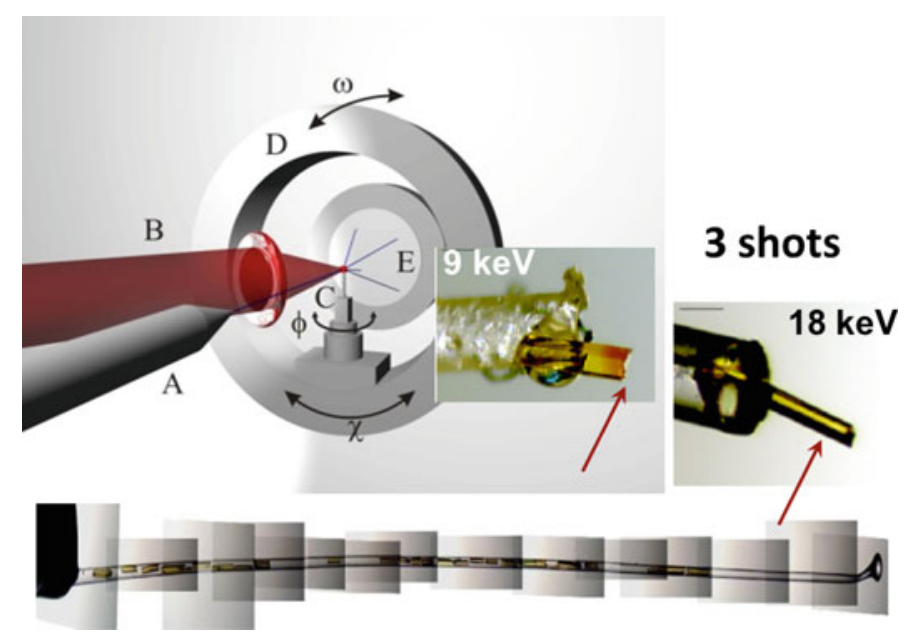

Fig. 17.5 References [17-52]: Ultrafast time-resolved small molecule crystallography at LCLS, XPP and CXI beamlines (interim set-up installed during the first in-house test phase of LCLS). Left side, top: used three circle diffractometer. Right side, top: organic crystals exposed to $9 \mathrm{keV}$ $\mathrm{X}$-ray radiation (single shot) inducing severe radiation damage and $18 \mathrm{keV}$ radiation allowing for the collection of various quasi Laue diffractograms with the Laue pink FEL beam under different orientations. Bottom: small molecule crystals lined up for a three-shot-serial type of crystallography experiment. The figure is adapted from the [8-10] and references therein

Since the studied materials are normally compounds of small amounts, in the presented approach highest quality crystals are stacked behind each other in a capillary (or other type of sample target holder) and high energy X-ray radiation is utilized for collecting high resolution diffraction patterns and minimizing accumulative radiation damage. Due to the monochromaticity of FEL X-ray beams even in its pink Laue mode, quasi Pink Laue diffraction pattern will be recorded for various orientations-allowing a precise determination of the orientation matrix of the small molecule crystals. Additionally, on a single shot base, the Bragg peak intensities are wavelength and X-ray intensity normalized (Fig. 17.5).

In the current example, unravelling the mechanisms of electron-transfer induced structural changes (ET), and the interplay of charge-transfer (CT) and structural reorganisations in complex molecular systems is of prime importance in both chemical and biological processes and has gained considerable importance over decades. ET/CT and the associated structural changes are pervasive, path to inevitably diverse processes occurring in nature, including light harvesting systems like photosynthesis to technological innovations such as solar energy converters and optical devices. It is challenging to trap the fleeting excited species or transient species and gain insight into the unprecedented dynamics which occurs in ultrafast time scale in the range of as to ps. Emerging scientific innovations in many synchrotrons and FELs, with high brilliance and extremely high photon flux have wide opened a new domain of research in investigating many ultrafast processes. Information about what happens 


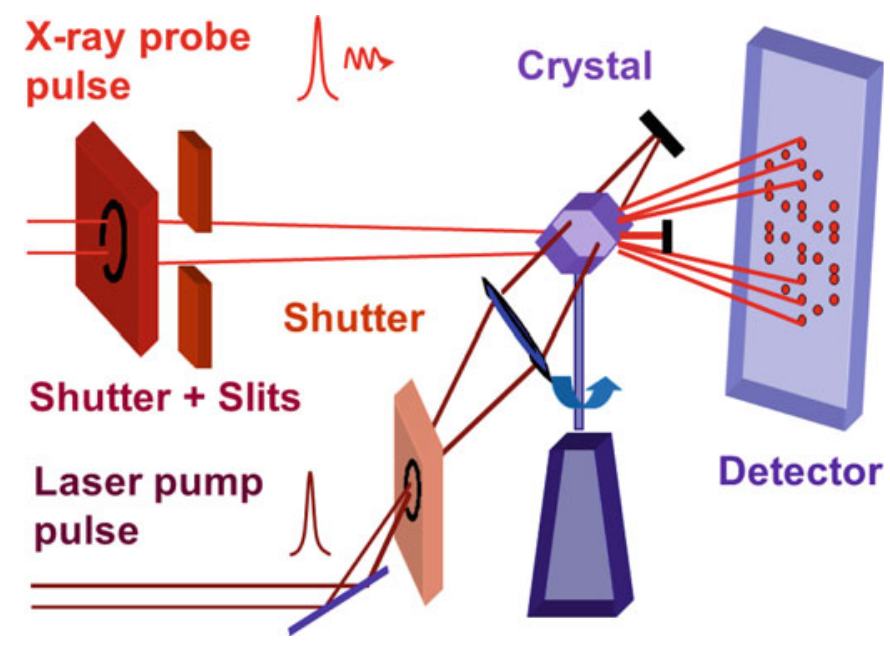

Fig. 17.6 References [17-52]: Optical laser pump/X-ray probe set-up for ultrafast X-ray crystallography. By varying the time-delay between optical laser pump and X-ray probe beam for different crystallographic orientations, X-ray diffraction snapshots as a function of time are collected. Adding the diffraction signals for one time-delay into one Ewald sphere allows an analysis of structural evolution as a function of time

immediately after the triggering of the reaction is satisfactory but to evaluate what happens next is crucial. In order to tackle these questions, we must know how fast the processes happen and what are the time scales of each processes we are interested in.

By employing time-resolved X-ray diffraction (TR-XRD) technique, the CT/ET reaction has been initiated by a laser pump pulse from the ground state to the excited state or the CT/ET state. The photo-induced subsequent structural changes have been monitored utilizing the pulsed structure of the X-ray beam by varying the time delay between the optical laser pump and X-ray probe pulses (pump/X-ray probe scheme) as been shown in Fig. 17.6.

In the following examples of structural dynamics of organic and metallo-organic systems by trapping charge transfer states using high brilliance Pink Laue timeresolved X-ray diffraction are presented. The photo-induced dynamics has been studied by looking from simple organic donor acceptor molecules (Fig. 17.7) to complex inorganic single crystalline systems. In the former the structural changes are induced by an ET/CT of an organic donor to an organic acceptor moiety, and in the later it is a induced by a metal to ligand charge transfer (MLCT) (see following chapter). Due to their high photo-conversion efficiencies and lifetimes, first are highly suited for solar cell developments, and last are highly suited as photo-catalysts.

The experiments have been performed combining high resolution static single crystal XRD studies utilizing a home-source (Bruker Apex II) system and P11 beamline of PETRA III at DESY. To map out the details of the potential landscapes, ultrafast, light-induced Laue diffraction studies of the pure organic 


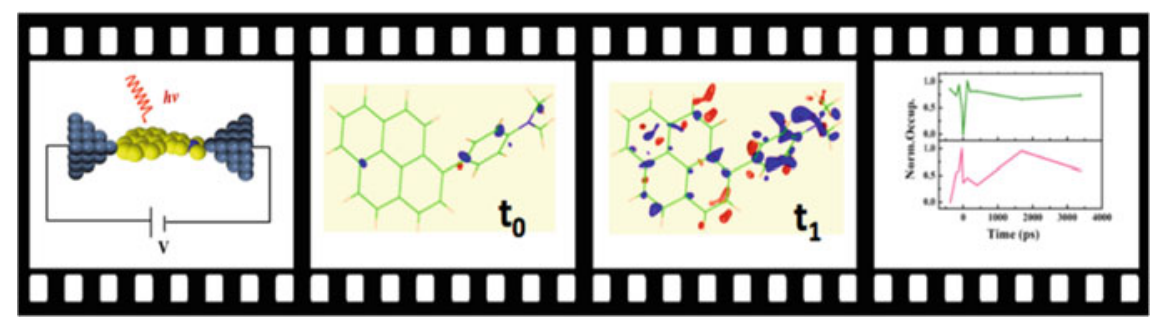

Fig. 17.7 References [17-52]: Molecular movie of a non-conventional molecular diode which cannot be described within the Born-Oppenheimer approximation. Within femtoseconds and nearly immediately after optical photo-absorption the electrons are rearranged towards a conducting state meanwhile the structure knocks into a tilted configuration. The figure is adapted from the [8-10] and references therein

system as well as the metal-complex have been performed at BioCARS, 14-ID beamline/Argonne (picosecond pink-Laue), ID09/ESRF (picosecond pink-Laue), XPP/CXI/LCLS (femtosecond pink-Laue) and P11/PETRA-III (picosecond, monochromatic). In the pure organic system within few hundreds of picoseconds electron density migration occurs and the structural changes are clearly visible from the photo difference map with prominent differences in the electron density maps at the electron donor and electron acceptor system (Fig. 17.7). In the metal-complex, it has been oberseved that upon photo-excitation the electron migration or the charge migration is mostly on the proximal atoms of the organic ligands from the metal center (not shown here).

Figure 17.7 depicts the refined result of such an experiment- the femtosecond structural dynamics or "molecular movie" of a molecular crystal, which consist of only light elements (carbon, nitrogen). The patented system has the most efficient optical light/electron transfer rate possible (100\%), by utilizing quantum effects such as electron and structural dynamics pathways which cannot be described through the conventional Born-Oppenheimer approximation.

\subsection{Applications in Energy Research}

Understanding this "beyond Born-Oppenheimer" behaviour and combining the properties of this type of system with smart semiconducting plastic types of compounds, it is possible to build flexible, solid, plastic-type of solar cells and organic light emitting diodes with very high efficiency (Fig. 17.8).

Both as a consequence of successive technical developments, and based on the chemical rules and time laws derived during the various method development process, it has become possible to optimize functional performances of solar cell organic materials and devices (Fig. 17.8). 


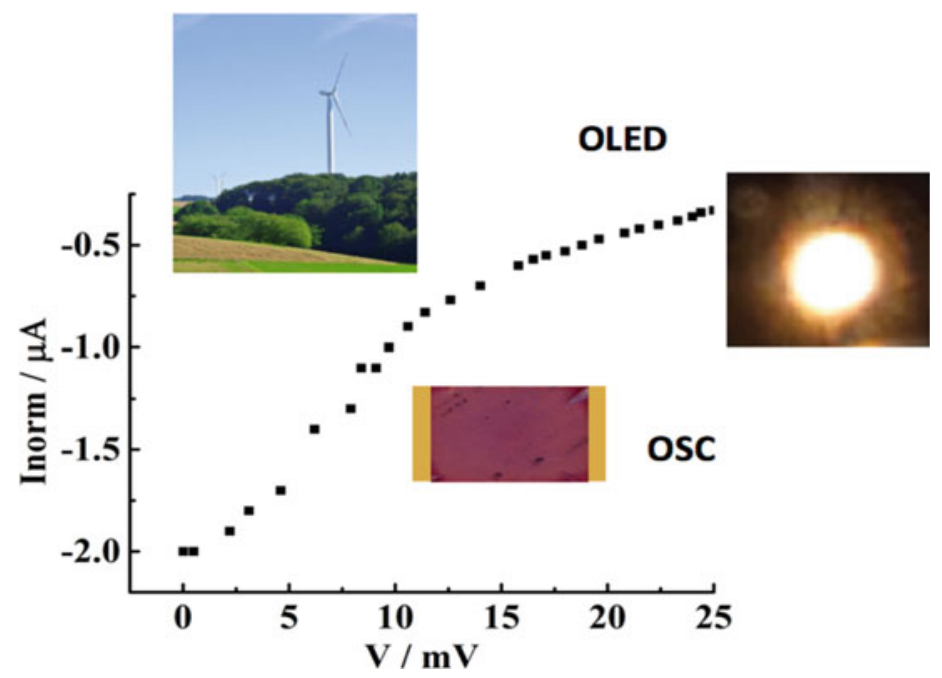

Fig. 17.8 References [53-59]: Once structural relaxation processes are understood the derived structural and dynamical properties can be utilized to improve functional dynamics performance allowing developing new classes of organic solar cells (OSC) (see current-voltage (I-V)curve) or organic light emitting diodes (OLED) based on plastic (see inset). The figure is adapted from the [8-10] and references therein

By moving the fundamental method developments into the application regime (again as a proof for the methods' developments), the circle of promises closes that 3rd and 4th generation X-ray sources may help to optimize strategies for modern material performances. In order to test whether the structural dynamics laws derived through the "molecular movie" approach can have direct consequences for applications of the molecular system, electronic devices such as organic solar cells and organic light emitting diodes have been built and Fig. 17.8 presents such efforts.

As can be seen on the current voltage (I-V) curve, when combining with semiconducting plastic material (which by itself is not photo active), efficient organic solar cells with high mechanic flexibility and cheap in production can be designed.

Since the time-resolved X-ray methods allow for detangling "local-to-global" and "global-to-local" structural responses, desired functional actions of a device like energy storage can be distinguished from "energy-eating" processes based on non-desired heating and energy quenching processes. Figure 17.7 presents the structural mechanisms underlying an optimized all-over organic solar cell. Small atomic changes on the light-absorbing chromophore unit lead to a complete switching of its functional dynamics - from light absorbing solar cell devices [53-59] to a light emitting organic diode [54]. In another example the understanding of the crystallization processes of organic material out of time-resolved X-ray diffraction (TR-XRD) studies has been influenced by the optimization of the recycling process of molten PET bottles to ultra-hard polyethylene [56]. Such ultra-hard plastic material is currently used in every 2 nd wind craft machine produced world-wide. 
The current examples emphasize, however, that the real world, functional materials, pharmaceuticals, catalysts or energy converting materials are not always crystalline and far from being periodically ideally arranged as it could look like when performing model type of investigations. If the intrinsic spatial resolution of the system does not allow for such detailed investigations, a combination of ultrafast X-ray spectroscopy and ultrafast X-ray diffraction or scattering as the "local to global approach" deliver configuration and charge information of the molecules studied [17-52, 60-76]. This approach will be described in the following chapter.

\subsection{From Local to Global: Ultrafast Multidimensional Soft X-ray Spectroscopy and Ultrafast X-ray Diffraction Shake Their Hands}

As ultrafast X-ray spectroscopy and X-ray diffraction can "shake their hands" in Xray Free-electron laser science, they open up new ways to study complex chemical reactions.

X-ray diffraction [17-59] and X-ray spectroscopy [60-76] are complementary techniques. X-ray spectroscopy allows probing the electronic properties in an element-, orbital- and site-specific way, for example bonding or oxidation state changes [63]. Since one gets local information for the system under investigation the method is referenced as the local approach. In X-ray diffraction the structural changes of the whole bulk are probed which is termed as the global approach. With these approaches it is possible to get the overall structural properties of the target system. Furthermore, by applying both methods more complete information can be obtained. However, to follow whole reaction pathways or reaction intermediates between the start and end of a reaction, the experimental approaches have to be extended using the time-resolved method, i.e. the pump-probe scheme, as described in the previous section and shown in Fig. 17.9.

With the availability of the first X-ray FEL, FLASH at DESY in Hamburg, Germany, it became possible to implement X-ray spectroscopy and diffraction for investigating ultrafast chemical reaction processes. In the following, we present two pioneering soft X-ray experiments performed at the FEL facilities FLASH and LCLS.

The first example is a time-resolved X-ray diffraction measurement on silverbehenate [60-76] with an outlook towards combination of the liquid jet with X-ray spectroscopy, the second example is a femtosecond time-resolved X-ray spectroscopy experiment on iron-pentacarbonyl $\left(\mathrm{Fe}(\mathrm{CO})_{5}\right)$ [78-81]. Figure 17.10a shows the apparatus which has been developed for such experiments at FELs. The ultrafast X-ray diffraction of a silver-containing redox system embedded in a supramolecular organic structure has been studied (Fig. 17.10b). The experiment is a proof-of-principle, utilizing FEL radiation for ultrafast X-ray diffraction of chemical systems in real-time. By investigating the time-evolution of the Bragg reflections (Fig. 17.10c) complex 


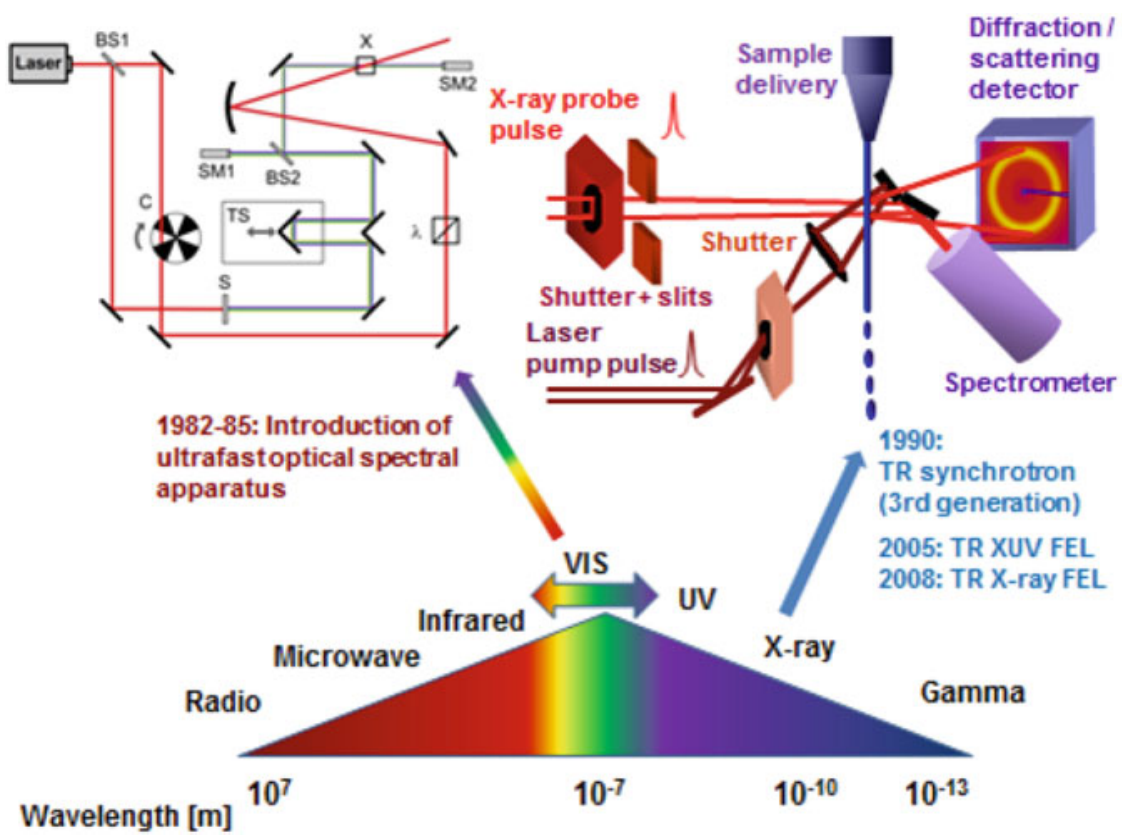

Fig. 17.9 References [60-76]: Principle of various types of pump-probe experiments applied to the optical region (left) and the corresponding type of experiments in the X-ray region (right). An optical laser pump initiates a chemical reaction and an optical (left) or X-ray laser pulse (right) probes the proceeding reaction pathways. Right: Both the X-ray spectroscopy and X-ray diffraction signal can be recorded, yielding complementary information. The figure is adapted from the [8-10] and references therein
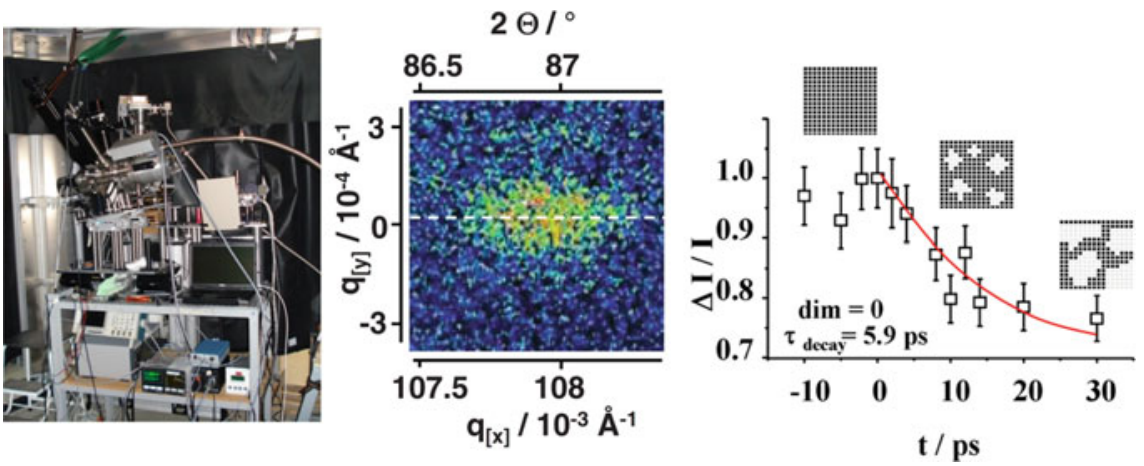

Fig. 17.10 References [60-76]: a The X-ray photon endstation at the FEL, FLASH at The modular built-up endstation has been used for the experiment presented in (b) and (c). b Bragg diffraction peak (110) of silver-behenate studied by single-shot FEL pulses. $\mathbf{c}$ The time-dependent behavior of the Bragg peak after photo-excitation. The figure is adapted from the [8-10] and references therein 
photo-induced transformation kinetics of partially photo-chemically induced and heat-propagation-influenced reaction kinetics has been found.

The decay curve depicts the propagation of the ultrafast transformation throughout the whole material. The black areas present the non-transformed material, the white areas the island of transformed material.

\subsection{Applications in Bimolecular Reaction Studies and Photocatalysis}

Another experiment in the field of soft X-ray spectroscopy has recently been worked out for studying photocatalysis. For pioneering time-resolved X-ray spectroscopy measurements the FLASH end station in Fig. 17.10 has been modified by adding a soft X-ray spectrometer in Rowland circle geometry [63, 66, 77-80]. This so called Liquid Jet (LJ) end station has then been successfully used in resonant inelastic X-ray scattering (RIXS) experiments on $\mathrm{Fe}(\mathrm{CO})_{5}$ at the LCLS-FEL at SLAC in Stanford, CA, USA. Similar end stations have been built to perform soft X-ray spectroscopy experiments at high flux X-ray facilities at DESY/Hamburg [15] and HZB/Berlin. In the above mentioned experiment [77-80], the dissociation of iron-pentacarbonyl $\left(\mathrm{Fe}(\mathrm{CO})_{5}\right)$ in ethanol has been studied in real-time. After optical excitation with 266 nm photons, Fig. 17.11a, $\mathrm{Fe}(\mathrm{CO})_{5}$ dissociates into iron-tetracarbonyl $\left(\mathrm{Fe}(\mathrm{CO})_{4}\right)$ and carbon monoxide (CO) under solvent-assistance. For every time-delay, the incident monochromatic FEL photon energy has been scanned over the Fe $2 p$ edge, and the $\mathrm{X}$-ray emission spectra have been recorded.

The time evolution was deduced from differences of the pumped (positive time-delay) and the un-pumped (negative time-delay) $\mathrm{Fe}(\mathrm{CO})_{5}$ emission spectra. Figure 17.11 summarizes the ethanol-assisted $\mathrm{Fe}(\mathrm{CO})_{5}$ photo-dissociation pathways and simulations are compared to the experiment. The complexity of reaction increases due to the formation and decay of a triplet state, where Fig. 17.11b-e summarises the evolution of the valence-electronic structure of $\mathrm{Fe}(\mathrm{CO})_{4}$ in ethanol upon femtosecond spin crossover and complex formation.

The involved orbitals are assigned according to the Fe $2 p$ and $3 d$, or ligand $2 p$ characteristics, and according to the symmetry along the $\mathrm{Fe}-\mathrm{CO}$ bonds. The star (*) in Fig. 17.11b, marks the antibonding orbitals of the electron configuration of the $\mathrm{Fe}(\mathrm{CO})_{5}$ ground state and the single-electron transitions of the laser pump-X-ray probe processes. The dissociation of $\left(\mathrm{Fe}(\mathrm{CO})_{5} \longrightarrow \mathrm{Fe}(\mathrm{CO})_{4}+\mathrm{CO}\right)$ is initiated by the optical $\mathrm{d}_{\pi} \rightarrow 2 \pi^{*}$ excitation. The RIXS measurements at the $\mathrm{Fe}_{3}$-absorption edge to final valence-excited states involves the probing of the $\mathrm{d}_{\pi} \rightarrow \mathrm{d}_{\sigma}^{*}$ transition. In Fig. 17.11(c, top), the difference RIXS spectra (RIXS intensity of incident photon energy versus energy transfer in $\mathrm{eV}$ ) of the summed pumped and un-pumped sample is illustrated. Figure 17.11(c, bottom) displays the time structure in the regions (1-4) in comparison to simulated populations of the excited (E) and triplet (T) states and ligated complex (L). Figure 17.11d shows the measured RIXS spectra for $\mathrm{Fe}(\mathrm{CO})_{5}$ 


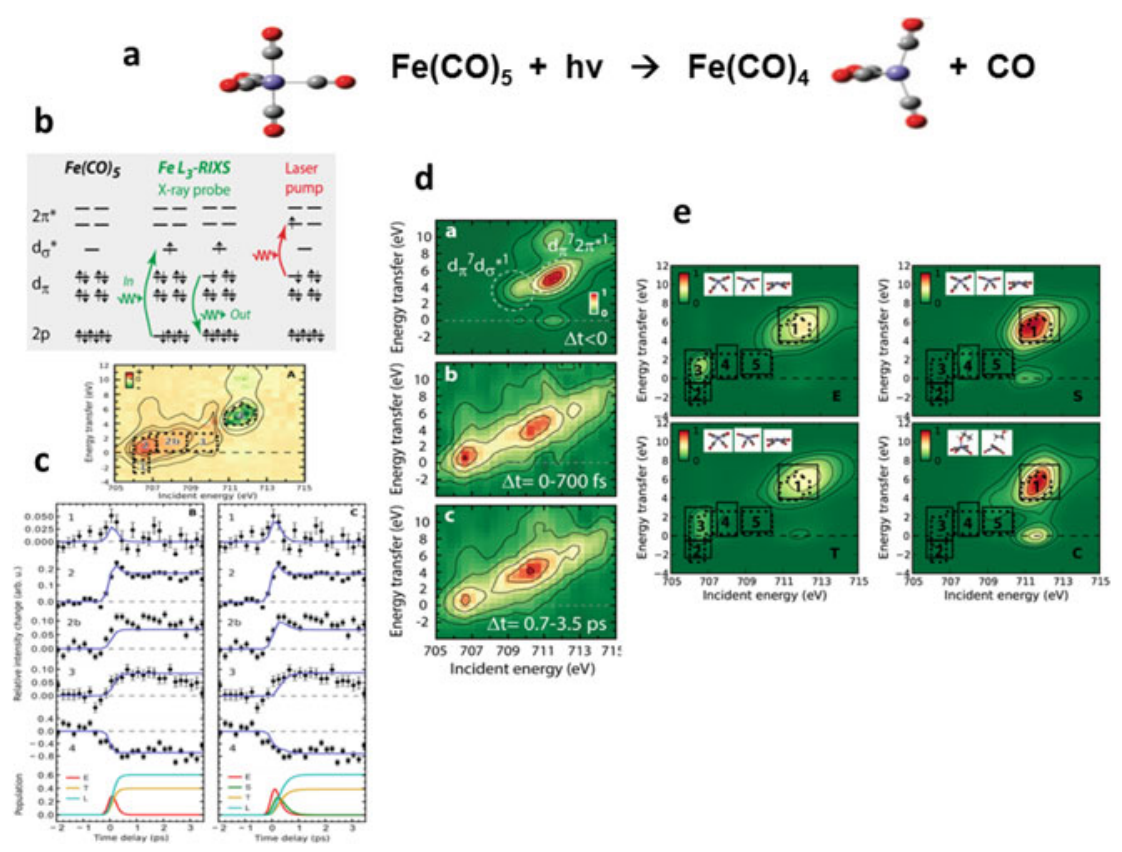

Fig. 17.11 References [77-80]: a $\mathrm{Fe}(\mathrm{CO})_{5}$ photo-dissociation. b-e Evolution of the $\mathrm{Fe}(\mathrm{CO})_{4} / \mathrm{EtOH}$ valence-electronic structure upon femtosecond spin crossover and complex formation. Term schema of the laser pump-X-ray probe experiment (b), measured (c, d) and simulated (e) RIXS scattering spectra, with and without included kinetic model on the excited state $(\mathrm{E})$, triplet state $(\mathrm{T})$ and ligand complex $(\mathrm{L}), \mathrm{Fe}(\mathrm{CO})_{4}$. d: The experimental $\mathrm{Fe} \mathrm{L}_{3}$-RIXS intensities (encoded in color) versus energy transfer and incident photon energy. (d, top) $\mathrm{Fe}(\mathrm{CO})_{5}$ ground state (negative delays, probe before pump, scattering to $\mathrm{d}_{\pi}^{7} \mathrm{~d}_{\sigma}^{* 1}$ and $\mathrm{d}_{\pi}^{7} 2 \pi^{* 1}$ marked by circles). (d, middle and bottom) Difference intensities for 0-700 fs and $0.7-3.5$ ps time delays, respectively. e Calculated $\mathrm{Fe} \mathrm{L}_{3}$ RIXS intensities (color coded as in (d) and molecular-orbital diagrams of $\mathrm{Fe}(\mathrm{CO})_{5}$ (ground state and hot), excited, triplet, and singlet $\mathrm{Fe}(\mathrm{CO})_{4}$ (all three non-complexed) and solvent complexed singlet $\mathrm{Fe}(\mathrm{CO})_{4}-\mathrm{EtOH}$. The figure is adapted from [8-10] and references therein

at negative time delays and the difference after delay intervals of $0-700 \mathrm{fs}$ and $0.7-$ $3.5 \mathrm{ps}$ respectively (color-encoded). By subtracting the negative time delay with a weight of 0.9 , the pumped contributions are isolated (top: $\mathrm{Fe}(\mathrm{CO})_{5}$, ground state (negative delays, probe before pump, scattering to $\mathrm{d}_{\pi}^{7} \mathrm{~d}_{\sigma}^{* 1}$ and $\mathrm{d}_{\pi}^{7} 2 \pi^{* 1}$ marked by middle/bottom: difference intensities for 0-700 fs and 0.7-3.5 ps time delays). The experimental data is compared to RIXS calculations displayed in Fig. 17.11e. Simulated $\mathrm{Fe} \mathrm{L}_{3}$-RIXS intensities and molecular-orbital diagrams of $\mathrm{Fe}(\mathrm{CO})_{5}$ in the ground and hot state and $\mathrm{Fe}(\mathrm{CO})_{4}$ in various valence excited states are depicted.

The $2 p \rightarrow$ LUMO resonance positions and $\mathrm{d}_{\pi} \rightarrow \mathrm{d}_{\sigma}^{*}$ RIXS transitions are marked by arrows. The RIXS pattern at early time evolution can only be reproduced when a complex between the $\mathrm{Fe}(\mathrm{CO})_{4}$ with the solvent is taken into account. 


\subsection{Applications in Unimolecular Liquid Phase Reaction Dynamics}

In the hard X-ray regime [81-89], the "local to global" approach has also been established by combining X-ray spectroscopy with X-ray scattering techniques. The ultrafast structural dynamics of various metal organic systems has been studied applying these techniques $[84,88,89]$.

\subsection{Applications in Bioelectronics, Aqueous and Prebiotics Reaction Dynamics}

In bioelectronics, aqueous and prebiotics reaction dynamics and biophysics, the ultrafast photon-in/photon-out developments utilizing high flux X-ray sources allow investigating the properties of biorelevant solvents and proteins during their structural reactions [90-108, 115, 116, 118, 121]. The literature-referenced examples include various types of small up to macromolecular model systems studied with X-ray radiation of ultrashort, high flux X-ray sources-X-ray scattering on quasi-periodic systems (Fig. 17.12) [90, 94-103], X-ray scattering on macromolecules (Fig. 17.13) and (Fig. 17.14) [90, 115, 116, 118, 121] and X-ray spectroscopy (Fig. 17.15) [91-93, 104-108].

Two examples of dynamical studies of soft condensed matter via high-flux timeresolved X-ray scattering will be given [90-108, 115, 116, 118, 121]: first, the studies of the dynamics of a phase transition of a liquid crystal-to-microemulsion system (Fig. 17.12) [95], and second, a real-time study of complex protein dynamics (Fig. 17.13/Fig. 17.14) [115, 116] will be given.

In liquid crystal type of soft condensed matter systems (Fig. 17.12), a manifold of phase-ordering transitions relevant to chemical and biological systems occur, ranging from liquids to self-assembled soft solids (like membranes or liquid crystals). In the present case the dynamics of the driving forces (activation energy and entropy) of a liquid crystal-to-microemulsion phase transition has been studied (Fig. 17.12 (left)). The purpose of this work was to clarify the influence of concentration effects of the amphiphilic molecules on the nature of these self-assembly processes.

By photosensitization of the model system (polyalkylglycolether $\left(\mathrm{C}_{10} \mathrm{E}_{4}\right)$, water, decane, and cyclohexane) with laser dyes, the phase transition could effectively be photo-induced and controlled through the absorption of optical photons (as a photoinduced phase transition, PIPT). The photo transformation conditions were chosen in such a way that the system was in thermal equilibrium as starting conditions.

By applying time-resolved photo small-angle X-ray scattering it has been found that the conversion process depends on the surfactant concentration and the activation energy, which is observable through the length of the induction time (Fig. 17.12 (right)). The phase-transition, though photo-triggered, is still diffusion controlled in the rate-determining steps. 

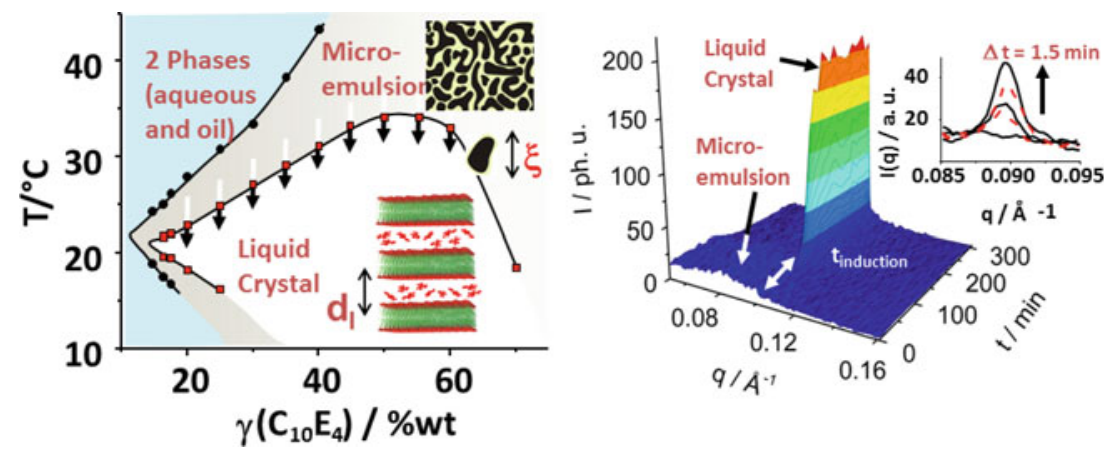

Fig. 17.12 References [90-95, 95-108, 115, 116, 118, 121]: (Left) Phase diagram of the system $\mathrm{C}_{10} \mathrm{E}_{4}$, water, $n$-decane, and cyclohexane at equal volume fractions of water and oil. Cyan represents an area where two phases coexist, dark gray the ME phase, and white the LC phase. The dots represent points of the phase boundaries. Arrows indicate the concentrations of the PIPT experiment. Inset: schematical drawings of the corresponding phases with the assignment of characteristic length scales like correlation length $\xi$ (ME) and distance d between the lamellae (LC). (Right) Photoinduced ME-LC phase transition investigated by TR-SAXS. The decrease of the ME and the increase of lamellar phase resemble in a concomitant increase of the discovered Bragg peak. The monoexponential nucleation and growth period is preceded by a concentration dependent induction time. Inset: Traces of the LC scattering. The figure is adapted from [8-10] and references therein

In the second example, X-ray scattering techniques, comprising of small-angle/wideangle X-ray scattering (SAXS/WAXS) techniques are increasingly used to characterize the structure and interactions of biological macromolecules and their complexes in solution (Figs. 17.13 and 17.14) [90, 94-103, 115, 116, 118, 121]. It is a method of choice to characterize flexible, partially folded and unfolded protein systems. X-ray scattering is the last resort for proteins that cannot be investigated by crystallography or NMR and acts as a complementary technique with different biophysical techniques to answer challenging scientific questions. The marriage of the X-ray scattering technique with the fourth dimension "time" yields structural dynamics and kinetics information for protein motions in hierarchical timescales from picoseconds to days (Fig. 17.13).

In the "fourth-dimension - time" of X-ray scattering technique (Fig. 17.13) the timescales accessible range from hours down to femtoseconds, even for investigating non-photoactive protein dynamics with different time-resolved X-ray scattering techniques. Various time-resolved and in-situ X-ray scattering techniques listed are complementary to the photon-triggered time-resolved X-ray scattering techniques and can be adaped to structural dynamics investigations of ubiquitous non-photoactive proteins.

Depending on the time scale of the system studied, it has been demonstrated that it is furthermore possible to merge X-ray scattering techniques like diffuse $\mathrm{X}$-ray scattering with pressure jump, temperature jump, electric field modulations, and structural freezing methods or, on the chemical modulation side, with, rapid mixing or photo-switching methods. 


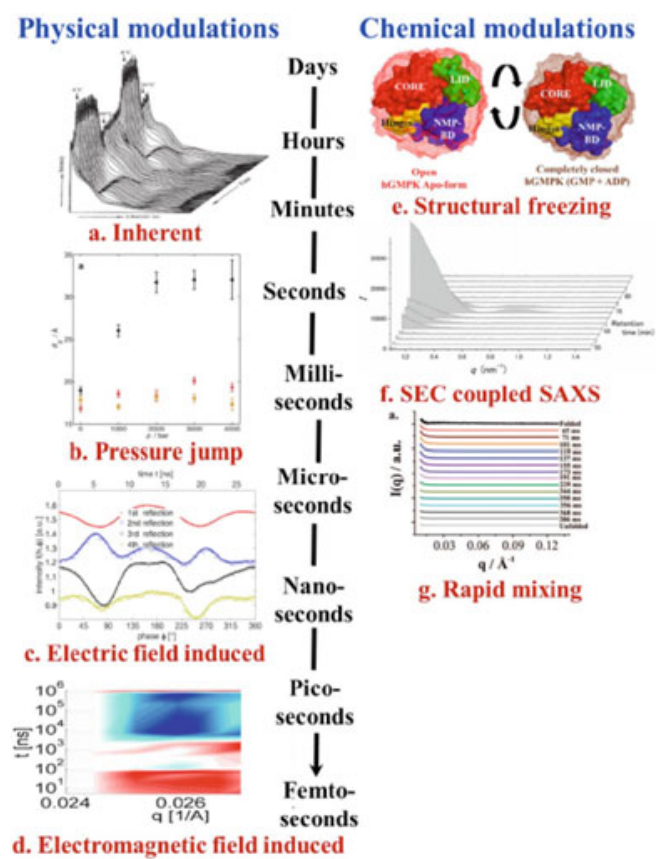

Fig. 17.13 References [90-108, 115, 116, 118, 121]: The "fourth-dimension - time" of X-ray scattering technique. The timescales accessible to investigate non-photoactive protein dynamics by using different time-resolved X-ray scattering techniques and the typical signal changes have been presented with representative published literature. a Inherent, b pressure-jump, c electricfield modulations, $\mathbf{d}$ electromagnetic field modulations, e structural freezing. f SAXS coupled with size-exclusion chromatography (SEC) technique and $\mathbf{g}$ rapid-mixing with the help of microfluidic devices. The figure is adapted from the $[8-10]$ and references therein

Figure 17.13 summarises typical X-ray scattering signal changes-inherent (a), as pressure-jump (b), in electric-field modulations (c), as electromagnetic field modulations (d), as structural freezing (e) and in small angle X-ray scattering experiments coupled with size-exclusion chromatography (SEC) technique (f). Special attention is given to rapid-mixing approaches with the help of microfluidic devices $(\mathrm{g})$ and (Fig. 17.14). Various techniques listed in the summary figure have independently been developed in neighbor projects of the collaborative research center (see "references" and references therein).

Figure 17.14 presents a scheme for a rapid-mixing time-resolved small angle $\mathrm{X}$-ray scattering experiments for the investigation of the ubiquitin unfolding process as model system and model process. Figure 17.14a presents the 20-microchannel continuous-flow microfluidic device and Fig. 17.14b the time-resolved small angle X-ray scattering (SAXS) setup for the kinetic ubiquitin unfolding studies (proving the secondary structure unfolding on the millisecond time scale), followed by 

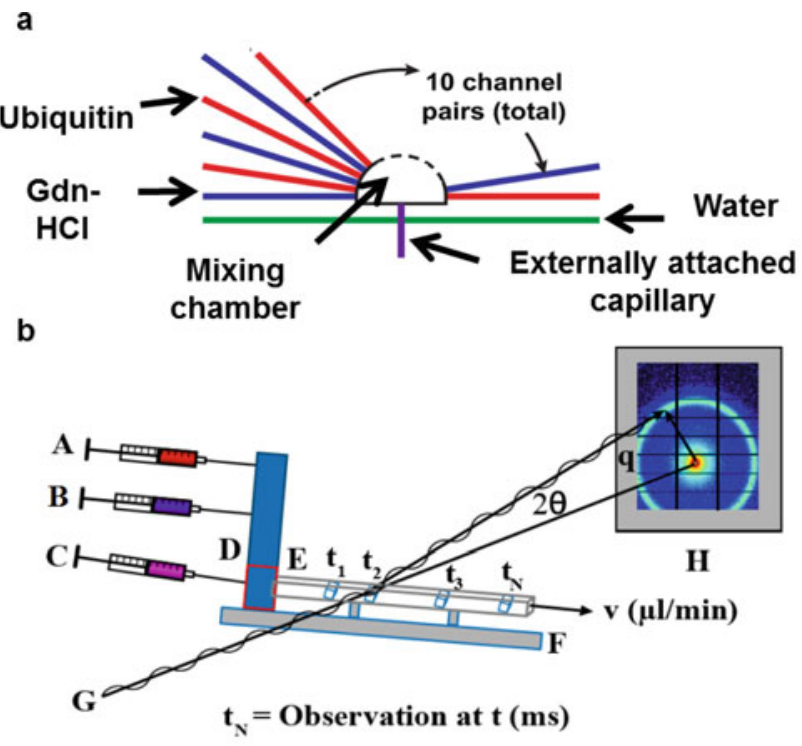

C

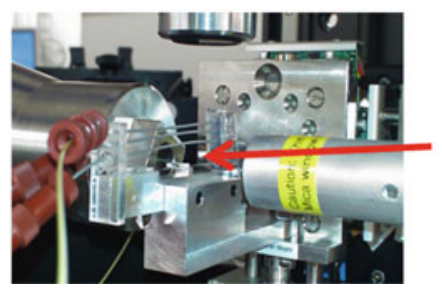

Integrated

20-microchannel

microfluidic

device

Fig. 17.14 References [91-93, 104-108]: Rapid-mixing TR-SAXS experiments to investigate the ubiquitin unfolding process. a 20-microchannel continuous-flow microfluidic device. b TR-SAXS setup for the kinetic ubiquitin unfolding studies (A: ubiquitin solution, B: $8 \mathrm{M}$ guanidinium- $\mathrm{HCl}$ solution, C: water, D: 20-microchannel microfluidics device, E: external glass capillary (X-ray probing area), F: capillary holder, G: X-ray beam, H: detector). c The integrated rapid mixing SAXS experimental setup at the cSAXS beamline, PSI Switzerland. The figure is adapted from [8-10] and references therein

the integrated rapid mixing SAXS experimental setup at the cSAXS beamline, PSI Switzerland.

The third example (of [91-93, 104-108]) concentrates on the use of multidimensional X-ray spectroscopy for studying the dynamics in soft condensed matter, here the dynamics of ions in aqueous solutions (Fig. 17.15). Hydration shells around ions are crucial for many fundamental biological and chemical processes. Their local physicochemical properties are quite different from those of bulk water and hard to probe experimentally.

By combining high-resolution soft X-ray spectroscopy using liquid jet technology as core hole clock spectroscopy method (Fig. 17.15 (left)) with molecular dynamics 

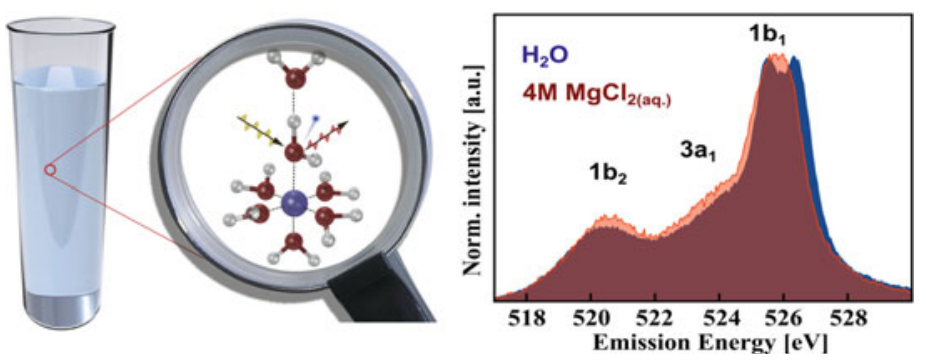

Fig. 17.15 References [90-108, 115, 116, 118, 121]: (Left) Principle of core-hole-clock spectroscopy/resonant inelastic X-ray scattering for investigating soft condensed matter reaction dynamics. (Right) The difference spectrum between $4 \mathrm{M} \mathrm{MgCl}_{2}$ and pure water is displayed. The difference represents the first hydration shell of water molecules around $\mathrm{Mg}^{2+}$ on the time scale of the oxygen core-hole-clock (5 fs). The figure is adapted from [8-10] and references therein

simulations and ab initio electronic structure calculations, at the molecular level the water-ion interaction in $\mathrm{MgCl}_{2}$ solution has been elucidated.

The results reveal that salt ions mainly affect the electronic properties of water molecules in close vicinity. Furthermore, in the first solvation shell the oxygen K-edge X-ray emission spectrum of water molecules differs significantly from that of bulk water. Ion-specific effects are identified by fingerprint features in the water X-ray emission spectra. While $\mathrm{Mg}^{2+}$ ions cause a bathochromic shift of the water lone pair orbital, the $3 p$ orbital of the $\mathrm{Cl}^{-}$ions causes an additional peak in the water emission spectrum at around $528 \mathrm{eV}$ (Fig. 17.15 (right)).

\subsection{Applications in Biophysics and Gas Phase Biomolecules}

Prolongating from the already presented techniques of combining X-ray scattering techniques like diffuse X-ray scattering with pressure jump, temperature jump, electric field modulations, and structural freezing methods or, on the chemical modulation side, with, rapid mixing or photo-switching methods and their successful application to biophysical questions $[90,94-103,115,116,118,121]$ or the application of core hole clock and multidimensional X-ray spectroscopy techniques towards aqueous and pre-biotics questions [91-93, 104-108] or novel liquid jet developments for biophysical research [120], in X-ray spectroscopy various other coupling techniques have been successfully proven.

The combination of synchrotrons or free-electron laser radiation with techniques, such as electrospray ionization mass spectrometry, allows deriving entirely novel experimental techniques for investigating macromolecules [109-121]. E.g. a mass spectrometric study on gas-phase ubiquitin at FLASH has revealed a fast local struc- 


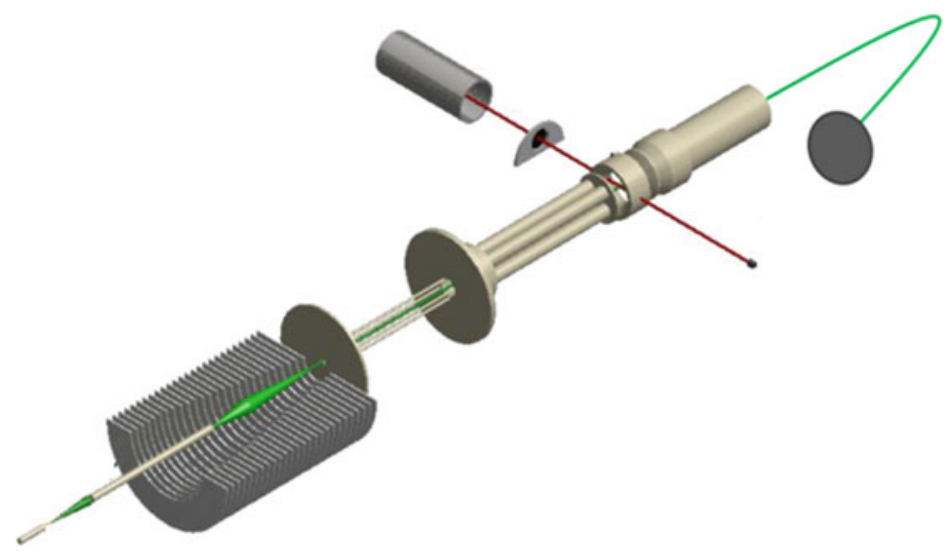

Fig. 17.16 References [109, 111-114, 119]: The mobile SMIS setup combines an electrospray ionization source, radio frequency (RF) mass filters, an RF trap and a mass spectrometer, which as a unity can be interfaced with different photon sources. The figure is adapted from [8-10, 114] and references therein

tural response, leading to small fragments with yields increasing linearly with photon intensity [109, 119].

Investigating the interaction of light with biologically relevant molecules has gained interest for a wide variety of research fields including photochemical reactions such as light harvesting as well as radiation damage in proteins and DNA related to cutting-edge cancer treatment techniques. However, in the condensed phase, disentangling direct and indirect radiation effects is often difficult [109-121].

In the beginning, studies on isolated polyatomic molecules in the gas phase were limited to small molecules, which are stable against thermal decomposition. In order to advance to more complex biomolecular systems, a novel apparatus has been designed. This mobile setup combines an electrospray ionization source, radio frequency (RF) mass filters, an RF trap and a mass spectrometer, which as a unity can be interfaced with different photon sources (see Fig. 17.16). Electrospray ionization introduces biomolecular ions from solution into the gas phase, allowing for studies of molecular systems in a well-defined state [109, 111-114, 119].

The coupling of electrospray ionization sources with synchrotrons [109, 111-114] and free-electron lasers [119] opens the way to the investigation of the electronic structure of biomolecular systems and of a fine description of their relaxation mechanisms in the VUV and soft X-ray energy range. The wide-ranging photon energy available at the synchrotrons enables systematic studies of ionization and dissociation as a function of the photon energy. Inner-shell excitations provide a localized site of energy deposition.

The extremely high photon flux and fs pulse duration offered by free-electron lasers allow studying the molecular properties in intense fields. Furthermore, using the assets of free-electron lasers in a pump-probe scheme enables the study of the dynamics of charge migration and charge transfer within gas-phase biomolecules. 
In the VUV to soft X-ray regime, strong indications have been found that photoabsorption within small peptides induces fast loss of aromatic amino acid side chains through repulsive states, occurring before redistribution of the internal energy. The very fast loss of side chains thus efficiently cools the residual peptide, and may enable the survival of early functional peptide substructures under photon irradiation. This dissociation is mainly caused by photoabsorption in the peptide backbone, which seems to trigger ultrafast charge migration to the side chains, without leading to fragmentation to the backbone itself [111-114, 119].

In the following, X-ray/peptide or X-ray/protein interactions have been studied as a function of peptide size. Small peptides like leucine enkephalin [109, 112] (five amino acid residues) dissociate into small immonium fragments, whereas bigger proteins like cytochrome c (106 amino acids residues) undergo only multiple ionizations and no fragmentation. The size dependency has been explained by considering that the average excess energy left in the peptide is redistributed over the ro-vibrational modes of the molecule and averaged over the various degrees of freedom. Therefore the larger proteins can handle much more energy due to more degrees of freedom to redistribute the energy.

First studies of a gas-phase protein (ubiquitin, 76 residues) at the free-electron laser in Hamburg, FLASH, has revealed two different photoabsorption regimes: nondissociative ionization in the few-photon regime (pulse energy of $0.1 \mu \mathrm{J}$ ), in contrast to side-chain losses in the multi-photon regime (pulse energy of $2.3 \mu \mathrm{J}$ ) [119]. The yields of these side-chain fragments increase linearly with the number of photons in the pulses. No region has been found where intermediate fragments due to backbone scission prevail. These effects suggest that in the XUV multiphoton regime, proteins seem to react as an ensemble of small peptides losing the side chains in fast local fragmentation processes.

Near edge X-ray absorption fine structure spectroscopy (NEXAFS) probes transitions between atomic core levels and orbitals of the molecular bonding states of intra-molecular neighbours. Therefore, NEXAFS is a powerful structural tool that provides information on the electronic structure. Data taken by near edge X-ray absorption mass spectrometry (NEXAMS) of gas-phase oligonucleotides [114], peptides [109, 112] (and references therein) and proteins [114c,118,119] show $\left(\pi^{*}, \sigma^{*}\right)$ transitions and Rydberg states similar to conventional NEXAFS spectra of thin films and liquids. Additional structural and dissociation dynamics within the molecules can be extracted from the NEXAMS information of the different individual ionization and dissociation products. Moreover, the gas-phase NEXAMS method can be sensitive to the secondary structure of proteins as shown in the study of melittin [113].

In the photoexcitation case of the protein melittin, the molecules end up singly ionized after excitation of the electron and singly Auger emission. The yields of the singly ionized parent peak of different initial charge states of melittin against the photon energy around the carbon $1 s$ edge are shown in Fig. 17.17 (top). In the photoionization case, the molecules end up doubly ionized after ionization of the electron into the continuum and singly Auger electron emission. The yields of the doubly ionized parent peak are shown in Fig. 17.17 (bottom). 

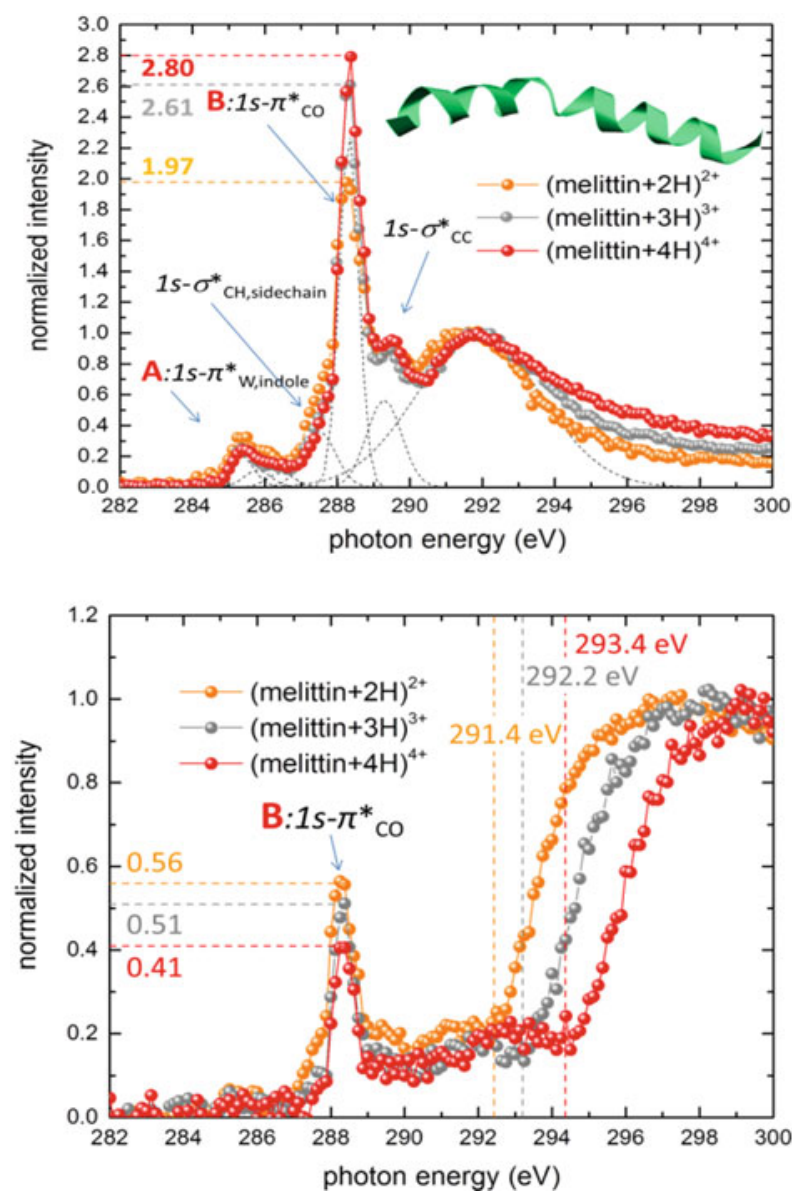

Fig. 17.17 References [109, 111-114, 119]: Yields/NEXAMS of different initial charge states of melittin against the photon energy. (top) NEXAMS spectra of the singly ionized parent peak around the carbon 1s edge. (bottom) NEXAMS spectra of doubly ionized melittin after ionizations of the electron into the continuum and singly Auger electron emission

A decrease of the resonance $\left(1 s-\pi_{\mathrm{CO}}^{*}\right)$ with increasing charge state is observed, an opposite trend as in the photoexcitation case. The NEXAMS properties and photoionisation behaviour are explained as additional ionization of the molecule by secondary electrons and the probability of the molecules being hit by these electrons depending on their geometries. Consequently, a helical and more compact structure with the charge state $2+$ the molecule has a higher probability to be hit again by an escaping electron compared to linear structures with four charges. 


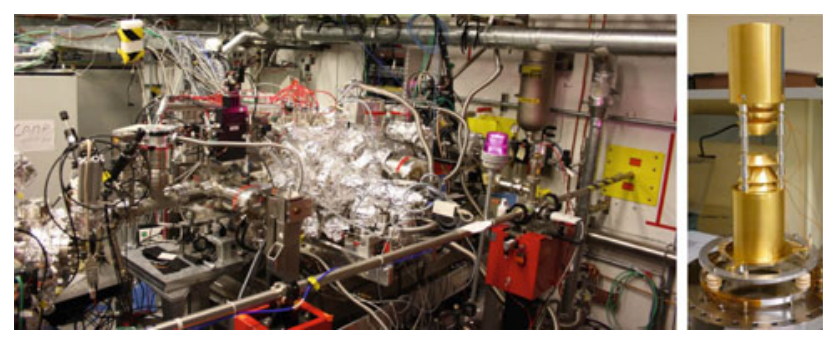

Fig. 17.18 References [122, 122-127, 127-163]: FLASH/CFEL-ASG MultiPurpose (CAMP) endstation at the AMO beamline at the LCLS in 2012. Since 2014, CAMP is a permanent endstation at FLASH/BL1 at DESY in Hamburg. Various experimental techniques can be employed in the instrument, including novel time-resolved $\mathrm{X}$-ray studies of chemical reactions in the gas phase. On the right side, CAMP's double-sided velocity-map-imaging spectrometer is shown. The figure is adapted from the $[8-10]$ and references therein

\subsection{Ultrafast Imaging of Unimolecular Gas-Phase Reactions}

The advent of X-ray free-electron lasers enabled not only novel studies in the condensed phase, as described in the first parts of this chapter, but also brought forward unprecedented possibilities to study dynamical processes in the gas phase. The very short and very intense X-ray pulses made it possible, for the first time, to probe ultrafast photo-induced molecular dynamics by electron or ion momentum spectroscopy following multiple, element-specific inner-shell absorption.

These new 4th generation light sources also called for novel, dedicated instrumentation (Fig. 17.18). To this end, different endstations have been developed, initially in particular for the use at the atomic, molecular, and optical physics (AMO) beamline, which was the first beamline to become operational at the LCLS [122, 122-163] in 2009. Several of the early, pioneering experiments from 2009 to 2012 have been performed at the AMO beamline in the CFEL-ASG MultiPurpose (CAMP) endstation [125, 127], see Fig. 17.18, which was developed within the Max-Planck Advanced Study Group (ASG) at the Center for Free-Electron Laser Science (CFEL) in Hamburg. Experiments in this instrument range from X-ray imaging of biomolecules, nanocrystals, and clusters [122, 125, 127-150] to (time-resolved) ion and electron spectroscopy on atoms and small gas-phase molecules [122, 122-127, 151-163]. Since 2014, CAMP is a permanent user endstation at FLASH/BL1 at DESY in Hamburg [124], and its successor, LAMP, has become operational at the AMO beamline at the LCLS [16b]. 


\subsection{Applications in Nanoscience and Multiphoton-Ionisation}

Moreover, the high-field physics (HFP) instrument has been developed at the LCLS [128-150], housing an ion momentum spectrometer and several electron time-offlight spectrometers mounted under different angles. It also offers a pulsed, supersonic molecular beam, delivering gas-phase molecules to the interaction region. The examples given in the following, as well as multiple other pioneering gas-phase studies have been conducted in the HFP instrument [122-150].

\subsection{Applications in Unimolecular Gas Phase Dynamics}

Gas-phase FEL experiments allow questioning fundamental definitions in chemistry, for example the investigation of processes beyond the Born-Oppenheimer approximation. As an example, a UV-pump, X-ray probe study of two complementary halomethane molecules with different photochemistry is shown here [122, 122-124, 126, 151-163].

In Fig. 17.19, the schematic potential energy curves (PECs) of iodomethane $\left(\mathrm{CH}_{3} \mathrm{I}\right)$ and fluoromethane $\left(\mathrm{CH}_{3} \mathrm{~F}\right)$ are displayed, illustrating that the different halogen species give rise to qualitatively different PECs [122, 152-155, 161, 163]. One reason for this is the considerably different electronegativity of iodine and fluorine, stabilizing the $\mathrm{C}-\mathrm{F}$ bond in contrast to the $\mathrm{C}-\mathrm{I}$ bond. Upon absorption of one $267 \mathrm{~nm}$ UV photon, $\mathrm{CH}_{3} \mathrm{I}$ dissociates into two neutral fragments, $\mathrm{CH}_{3}+\mathrm{I}$, whereas in $\mathrm{CH}_{3} \mathrm{~F}$, no PEC is resonantly accessible at $4.6 \mathrm{eV}$. In the latter case, absorption of at least three UV photons in the same molecule populates several higher-lying ionic PECs, also resulting in dissociation of the molecules.

After a tunable time delay, an intense $\mathrm{X}$-ray pulse $(727 \mathrm{eV}, 1 \mathrm{~mJ})$ probes the dissociating system by ionizing predominantly the iodine $(3 d)$ or the fluorine $(1 s)$ level, respectively, because of their large absorption cross section (3.3 Mb for I and $0.4 \mathrm{Mb}$ for $\mathrm{F}$, compared to $0.1 \mathrm{Mb}$ for $\mathrm{CH}_{3}$ ), resulting in a localized positive charge on the halogen $[122,152-155,161,163]$.

At these very high X-ray intensities, a single molecule can absorb many photons, such that very highly charged ions up to $\mathrm{I}^{21+} / \mathrm{F}^{4+}$ and $\mathrm{C}^{4+}$ are created.

As the charge is initially created locally at the halogen atom though, the fact that highly charged carbon ions are also detected already shows that the charge rearranges within the molecule before or during the fragmentation.

In Fig. 17.20, the calculated electrostatic potentials of an $\mathrm{I}^{6+}+\mathrm{CH}_{3}$ are plotted for three different internuclear distances between the two fragments, together with the binding energy of the highest occupied orbital. In the intact molecule (a), the electrons are delocalized, but as the fragments move apart the potential barrier rises, until at a certain critical distance (b), it reaches the electron binding energy. 

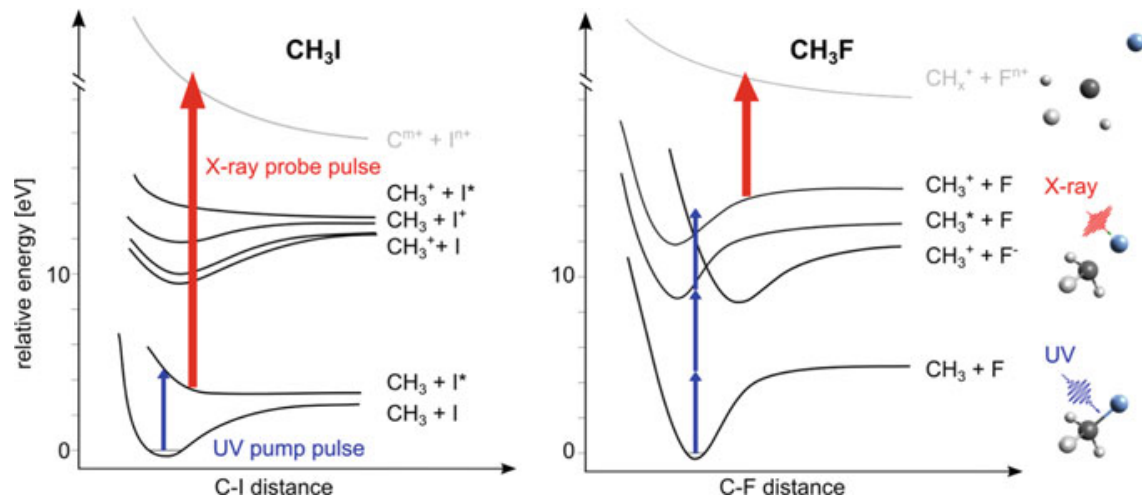

Fig. 17.19 References [122, 122-127, 151-163]: Schematic potential energy curves for iodomethane (left) and fluoromethane (right). Absorption of one $267 \mathrm{~nm}$ photon in $\mathrm{CH}_{3} \mathrm{I}$ leads to resonant population of a repulsive neutral state, whereas multi-photon $\mathrm{UV}$ absorption in $\mathrm{CH}_{3} \mathrm{~F}$ populates to several higher-lying ionic states. After a given time delay, these states are probed by Coulomb explosion following inner-shell ionization of the respective halogen atom by one or several X-ray photons, probing the transition from a molecule to isolated atoms. The figure is adapted from the $[8-10]$ and references therein

Therefore, for larger distances (c) the electrons can classically be regarded as localized at one of the two fragments. It is this transition from a bound molecule to isolated atoms that is probed by time-resolved ion spectroscopy $[122,152-155,161$, 163].

The delay-dependent time-of-flight peaks of selected ions of iodomethane and fluoromethane are shown in Fig. 17.21. It is evident that the fragmentation patterns of the two molecules are qualitatively different. For iodine charge states $\geq \mathrm{I}^{4+}$, the appearance of low-energy ions at positive delays is clearly visible (channel 3 in Fig. 17.21a).

Signatures of long-distance intramolecular electron transfer have been observed for both, $\mathrm{CH}_{3} \mathrm{I}$ and $\mathrm{CH}_{3} \mathrm{~F}$, and the reconstructed critical distances (up to $15 \AA$ for $\mathrm{I}^{21+}$ ) are in good agreement with a classical over-the-barrier model.

These ions originate from the pump-probe process as indicated for iodomethane in Fig. 17.21, and can be used to extract the critical internuclear distance, up to which electron transfer from methyl to iodine is classically allowed for a given charge state [122, 152-155, 161, 163].

Two other channels can be seen in Fig. 17.21 that correspond to Coulomb explosion of intact molecules by only the FEL (1) and to ionic dissociation induced by multi-photon UV absorption (2), as illustrated for fluoromethane in Fig. 17.21, which also occurs with a lower probability in $\mathrm{CH}_{3} \mathrm{I}$. The low-energy channel is absent in the fluorine ions. 


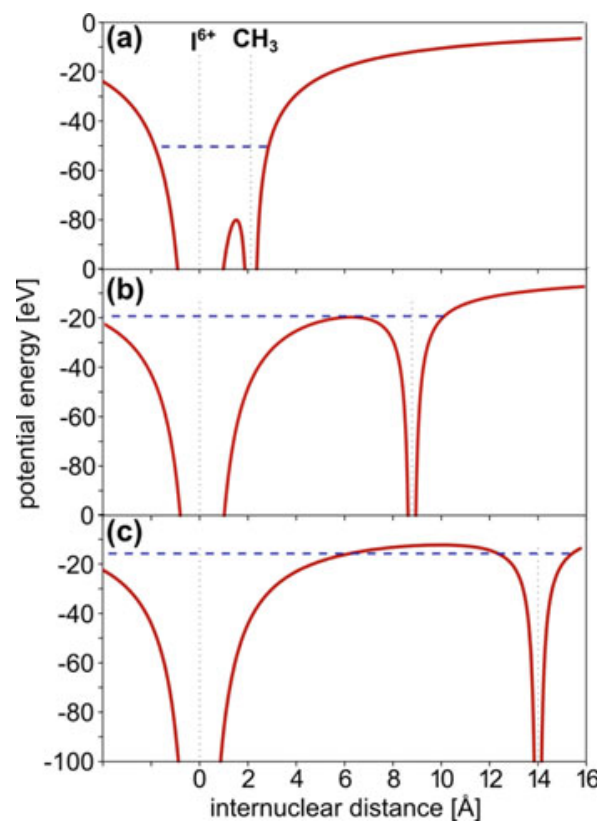

Fig. 17.20 References [122, 122-127, 151-163]: Calculated Coulomb potentials for an $\mathrm{I}^{6+}$ atom and a neutral methyl radical for a the equilibrium distance, $\mathbf{b}$ the cricital distance (see text) and $\mathbf{c}$ for isolated atoms (in a classical picture). The dashed blue line indicates the energy of the electron in the highest occupied orbital. The figure is adapted from the [8-10] and references therein
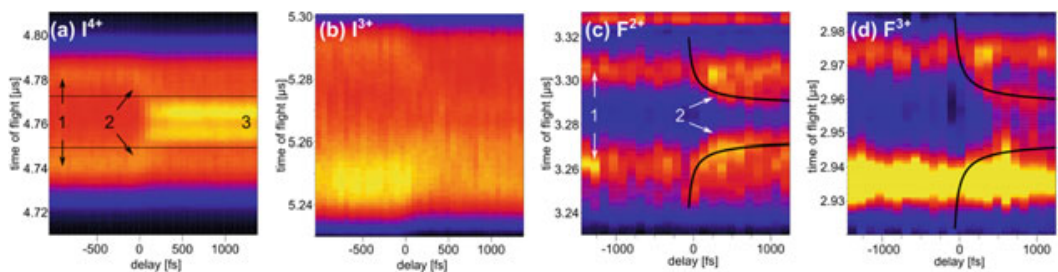

Fig. 17.21 References [122, 122-127, 151-163]: a-b Time-of-flight spectra as a function of the pump-probe delay for selected fragments of iodomethane and fluoromethane. Different fragmentation channels are indicated by 1, 2, 3 (see text). Additionally, in (c) and (d), calculated delaydependent time-of-flight curves are overlaid with the data, corresponding to an asymptotic kinetic energy of $0.4 \mathrm{eV}$. Positive delays correspond to the UV pulse arriving before the X-ray pulse. The figure is adapted from the [8-10] and references therein 


\subsection{Outlook and Conclusion: First High-Repetition Frequency, Ultrafast Hard and Soft X-ray Studies of Chemical Reactions at the European X-ray Free Electron Laser}

The current chapter tried to give a comprehensive summary of the very first and pioneering developments of chemical research tools utilizing soft and hard X-ray Free Electron Laser radiation. The structural dynamics and "molecular movie" concept has been introduced and confirmed in various states of matter and in different type of chemical reactions: in the gas phase (unimolecular), in the liquid phase (uni- and bimolecular) and in the solid state.

Novel experimental FEL concepts have been introduced which needed to be developed for the different chemical systems and reaction classes, and their pioneering applications in the various fields of FEL chemistry studies-from molecular reaction studies, through photocatalysis to energy research and biophysics-have been demonstrated. All reported experiments were of pioneer type concerning its kind. It has successfully been shown that it is possible to follow chemical reactions with FEL radiation in real time in the gas phase, in the liquid phase, and in the solid phase. Comparisons to other exiting techniques developed at free-electron laser sources have been given.

As due to the coincidence between the time, where FELs in the soft and hard X-ray regime came first into operational mode (2005-2018), and the start and running time of the Collaborative Research Center SFB755 Nanoscale Photonic Imaging (2007-2019), FEL milestones for chemical research have directly and right-on-time been reported within the SFB755. From our side, therefore, the SFB covers the most precious "life-time" of our experimental efforts so far, making it most important, essential and special for us as intellectual exchange and scientific support platform, and as a common effort of the Göttingen Campus. Every further development being sketched in the last paragraph can be built on the scientific construction platform supported by the SFB.

Since end 2017 the European X-ray Free-electron Laser as the first FEL of the 2nd generation is operationable. It unifies $\mathrm{MHz}$ repetition frequency capabilities with highest brilliance, stable time-synchronisation (allowing for view femtosecond time-resolved experiments), highest degree of coherence, tunability etc. allowing for experiments in an evolution to pioneering experiments of 1st generation FELs but also towards novel experimental strategies employing multidimensional X-ray spectroscopy or ultrafast inelastic scattering techniques. In the "molecular movie" field first feasibility and demonstration experiments have been performed and are discussed in the context of existing X-ray FEL chemistry studies. In the next 10 years novel superconducting LINAC technologies will come in operation (i.e. in LCLS-II) allowing for expanding existing techniques and a shift of experimental paradigm from proof-of-concept studies towards sample-curiosity driven X-ray experiments. 


\subsection{Acknowledgements}

The Helmholtz Society is thanked for continuous financial support and DESY for preferred access to X-ray instrumentation. DESY staff is thanked for their competent help in large scale facility technical and computer support. Up to 2017, the Max Planck Society is acknowledged for continuous financial support. The workshops and chemical facility of the Max Planck Institute for Biophysical Chemistry is thanked for their competent help in chemical synthesis, analysis and technical design of the micro apparatus and computer support.

When the SFB755 "Nanoscale Photonic Imaging" started, in 2006, synchrotron researchers faced their next challenge in developing and proving X-ray Free Electron Laser Science. Throughout and fully, over the last 12 years research work of method developments utilizing X-ray free-electron lasers and synchrotron research (method development) as been presented in this chapter have been financially supported by the Deutsche Forschungsgemeinschaft within the Collaborative Research Center SFB755 "Nanoscale Photonic Imaging" (project B03 and project B10). Systems- and sample-related research work also presented in this chapter have been funded through the Collaborative Research Center SFB1073 "Atomic-scale Control of Energy Conversion" (project B06 and C02). Furthermore, the German Academic Exchange Service DAAD, the Alexander von Humboldt Foundation AvH, the Fonts of the Chemical Industry FCI, the Aventis Foundation, "Niedersachsen Vorab", the Peter-PaulEwald Fellowship program of the Volkswagen Foundation (No 87008) are thanked for financial support.

The independent young investigator groups of Daniel Rolles ("Watching Chemistry in Action" (VH-NG-904, 2012-2017), now Kansas State U) and Sadia Bari ("Structure and Dynamics of Gas Phase Biomolecules" (VH-NG-1104, 2016-now) have additionally financially been supported by the project B03 of the SFB755 (see "references").

The Advanced Study Group of the Max Planck Society is thanked for financial support 2006-2011, the Initiative and Networking Fund of the Helmholtz Association is thanked from 2012 on (programs: VH-NG-1104, NV-NG-904, HG-recruitment, HG-Innovation "ECRAPS", HG-Innovation "HESEB/SESAME", DSF, DASHH, DGP, CMWS).

The German-Israeli Foundation for Scientific Research and Development (GIF) and the Technion Society/BMBF are thanked for support in education and research.

Over the last decade, beamline staff of the Helmholtz Center Berlin (HZBProf. A. Foehlisch and his team) is thanked for the fruitful collaborations, experimental support and hospitality. Beamline responsibles of the European Synchrotron Radiation Facility (ID09, ID11, ESRF-Prof. M. Wulff and his team), the Advanced Photon Source (ID14, APS-V. Srajier and the team), the Swiss Light Source (cSAXS (A. Menzel), SLS), the Stanford Synchrotron Radiation Facility (SPEAR, SSRL), PETRA III (P01 (H. Yavas), P03 (S. Roth), P04 (J. Viefhaus), P10 (M. Stumpf) and P11 (A. Burkhardt)) and the Advanced Light Source (ALS) are thanked for their fruitful collaborations, experimental support and hospitality. 
Staff and beamline scientists of the free-electron laser FLASH (BL1-BL3, CAMP (B. Erk); E. Ploenjes, B. Manschwetus, R. Treusch, M. Kuhlmann and the teams) @ DESY, staff and beamline scientists of the free-electron laser LCLS (AMO (J. Bozek, C. Bostedt), SXR (B. Schlotter, J. Turner), XPP (D. Fritz) and CXI (M. Messerschmidt, S. Boutet)) @ SLAC, staff and beamline scientists of the Free Electron Laser SACLA @ SPRING-8/Riken and staff and-finally—the European X-ray free-electron laser European XFEL in Schenefeld and their beamline staff (FXE (C. Bressler), SPB (A. Mancuso), SCS (A. Scherz) and SQS (M. Meyer)) are deeply acknowledged for their collaborations, support and hospitality with the DESY/FSSCS group members.

Use of the Linac Coherent Light Source (LCLS), SLAC National Accelerator Laboratory, is supported by the U.S. Department of Energy, Office of Science, Office of Basic Energy Sciences under Contract No. DE-AC02-76SF00515.

\section{References}

1. Madey, J.M.J.: Stimulated emission of bremsstrahlung in a periodic magnetic field. J. Appl. Phys. 42(5), 1906-1913 (1971). https://doi.org/10.1063/1.1660466

2. Benson, S., Deacon, D.A.G., Eckstein, J.N., Madey, J.M.J., Robinson, K., Smith, T.I., Taber, R.: Review of recent experimental results from the stanford $3 \mu \mathrm{m}$ free-electron laser. Le J. de Physique Colloques 44(C1), C1-353-C1-362 (1983). https://doi.org/10.1051/jphyscol: 1983128

3. Halbach, K.: Permanent magnet undulators. Le J. de Physique Colloques 44(C1), C1-211C1-216 (1983). https://doi.org/10.1051/jphyscol:1983120

4. Kondratenko, A.M., Saldin, E.L.: Linear theory of free-electron lasers with fabry-perot resonators. Sov. Phys.-Tech. Phys.(Engl. Transl.);(United States) 27(2) (1982)

5. Luccio, A., Pellegrini, C.: One dimensional numerical simulation of a free-electron laserstorage ring system. Le J. de Physique Colloques 44(C1), C1-373-C1-374 (1983). https:// doi.org/10.1051/jphyscol:1983133

6. Madey, J.M.J.: Application of transverse gradient wigglers in high efficiency storage ring fel's. Le J. de Physique Colloques 44(C1), C1-169-C1-178 (1983). https://doi.org/10.1051/ jphyscol:1983116

7. Sprangle, P., Smith, R.A.: Theory of free-electron lasers. Phys. Rev. A 21(1), 293-301 (1980). https://doi.org/10.1103/physreva.21.293

8. Bari, S., Boll, R., Idzik, K., Kubicek, K., Raiser, D., Veedu, S.T., Yin, Z., Techert, S.: Ultrafast time structure imprints in complex chemical and biochemical reactions. R. Soc. Chem. (2017). https://doi.org/10.1039/9781782624097

9. Techert, S.: Handbook for using free-electron lasers in chemical research. Struct. Dyn. (2019). In press

10. Techert, S.: Tutorial lecture, iff spring school (2019). https://www.fz-juelich.de/SharedDocs/ Termine/PGI/EN/2019/2019-03-11-IFFSpringSchool-50th.html

11. Schmatz, S.: Four-mode calculations of resonance states of intermediate complexes in the $\mathrm{SN} 2$ reaction $\mathrm{Cl}^{-}+\mathrm{CH}_{3} \mathrm{Cl}$ to $\mathrm{ClCH}_{3}+\mathrm{Cl}^{-}$. J. Chem. Phys. 118(1-3), 4499-4516 (2003). https://doi.org/10.1063/1.1541626

12. Techert, S.: First-, second- and third-order correlation function in time-resolved X-ray diffraction experiments. J. Appl. Crystallogr. 37(3), 445-450 (2004). https://doi.org/10.1107/ s0021889804007381

13. Techert, S., Schmatz, S.: Time-resolved X-ray scattering and the observation of intramolecular reaction dynamics in liquids. Zeitschrift für Physikalische Chem. 216(10-12), 575-583 (2002). https://doi.org/10.1515/zpch-2015-0610 
14. Techert, S., Schotte, F., Wulff, M.: Picosecond X-ray diffraction probed transient structural changes in organic solids. Phys. Rev. Lett. 86(10), 2030-2033 (2001). https://doi.org/10.1103/ physrevlett.86.2030

15. (a) flash; (b) lcls, (c) sacla, (d) swissfel, (e) european xfel

16. Debnarova, A., Techert, S., Schmatz, S.: Ab initio treatment of time-resolved X-ray scattering: application to the photoisomerization of stilbene. J. Chem. Phys. 125(22), 224,101-224,108 (2006). https://doi.org/10.1063/1.2400231

17. See Ref. [28] pp. 335-337

18. Altarelli, M., Brinkmann, R., Chergui, M., Decking, W., Dobson, B., Düsterer, S., Grübel, G., Graeff, W., Graafsma, H., Hajdu, J., Marangos, J., Pflüger, J., Redlin, H., Riley, D., Robinson, I., Rossbach, J., Schwarz, A., Tiedtke, K., Tschentscher, T., Vartaniants, I., Wabnitz, H., Weise, R.W., Witte, H.K., Wolf, A., Wulff, M., Yurkov, M.: The european X-ray free-electron laser (2007)

19. Blome, C., Tschentscher, T., Davaasambuu, J., Durand, P., Techert, S.: Femtosecond timeresolved powder diffraction experiments using hard X-ray free-electron lasers. J. Synchrotron Radiat. 12(6), 812-819 (2005). https://doi.org/10.1107/s0909049505026464

20. Blome, C., Tschentscher, T., Davaasambuu, J., Durand, P., Techert, S.: Ultrafast time-resolved powder diffraction using free-electron laser radiation. In: AIP Conference Proceedings. AIP (2007). https://doi.org/10.1063/1.2436292

21. Busse, G., Tschentscher, T., Plech, A., Wulff, M., Frederichs, B., Techert, S.: First investigations of the kinetics of the topochemical reaction of p-formyl-trans-cinnamic acid by time-resolved X-ray diffraction. Faraday Discuss. 122, 105-117 (2002). https://doi.org/10. 1039/b202831j

22. Cavalieri, A.L., Fritz, D.M., Lee, S.H., Bucksbaum, P.H., Reis, D.A., Rudati, J., Mills, D.M., Fuoss, P.H., Stephenson, G.B., Kao, C.C., Siddons, D.P., Lowney, D.P., MacPhee, A.G., Weinstein, D., Falcone, R.W., Pahl, R., Als-Nielsen, J., Blome, C., Düsterer, S., Ischebeck, R., Schlarb, H., Schulte-Schrepping, H., Tschentscher, T., Schneider, J., Hignette, O., Sette, F., Sokolowski-Tinten, K., Chapman, H.N., Lee, R.W., Hansen, T.N., Synnergren, O., Larsson, J., Techert, S., Sheppard, J., Wark, J.S., Bergh, M., Caleman, C., Huldt, G., van der Spoel, D., Timneanu, N., Hajdu, J., Akre, R.A., Bong, E., Emma, P., Krejcik, P., Arthur, J., Brennan, S., Gaffney, K.J., Lindenberg, A.M., Luening, K., Hastings, J.B.: Clocking femtosecond X-rays. Phys. Rev. Lett. 94, 11 (2005). https://doi.org/10.1103/PhysRevLett.94.114801

23. Collet, E., Lemee-Cailleau, M.H., Cointe, M.B.L., Cailleau, H., Wulff, M., Luty, T., Koshihara, S.Y., Meyer, M., Toupet, L., Rabiller, P., Techert, S.: Laser-induced ferroelectric structural order in an organic charge-transfer crystal. Science 300(5619), 612-615 (2003). https://doi. org/10.1126/science.1082001

24. Davaasambuu, J., Busse, G., Techert, S.: Aspects of the photodimerization mechanism of 2, 4-dichlorocinnamic acid studied by kinetic photocrystallography? J. Phys. Chem. A 110(9), 3261-3265 (2006). https://doi.org/10.1021/jp054723m

25. Davaasambuu, J., Durand, P., Techert, S.: Experimental requirements for light-induced reactions in powders investigated by time-resolved x-ray diffraction. J. Synchrotron Radiat. 11(6), 483-489 (2004). https://doi.org/10.1107/s090904950402463x

26. Davaasambuu, J., Wright, J., Soerensen, H.O., Schmidt, S., Poulsen, H.F., Techert, S.: An application of multigrain approaches to the structural solution of grains from polycrystalline samples. Solid State Phenom. 288, 119-123 (2019). https://doi.org/10.4028/www.scientific. net/SSP.288.119

27. Debnarova, A., Techert, S., Schmatz, S.: Contribution of coulomb explosion to form factors and mosaicity spread in single particle X-ray scattering. Phys. Chem. Chem. Phys. 16(2), 792-798 (2014). https://doi.org/10.1039/c3cp54011a

28. Fuest, H.: Built-up of a time correlated single photon counting apparatus for optical control in photo crystallography (2012)

29. Hallmann, J.: Photoinduced solid-state reactions-spectroscopy and X-ray diffraction analysis (2010) 
30. Hallmann, J., More, R., Morgenroth, W., Paulmann, C., Kong, Q., Wulff, M., Techert, S.: Evidence for point transformations in photoactive molecular crystals by the photoinduced creation of diffuse diffraction patterns. J. Phys. Chem. B 116(36), 10996-11003 (2012). https://doi.org/10.1021/jp3020832

31. Hallmann, J., Morgenroth, W., Paulmann, C., Davaasambuu, J., Kong, Q., Wulff, M., Techert, S.: Time-resolved X-ray diffraction of the photochromic $\alpha$-styrylpyrylium trifluoromethanesulfonate crystal films reveals ultrafast structural switching. J. Am. Chem. Soc. 131(41), 15018-15025 (2009). https://doi.org/10.1021/ja905484u

32. Hallmann, J., Techert, S.: Photoluminescence properties of a molecular organic switching system. J. Phys. Chem. Lett. 1(6), 959-961 (2010). https://doi.org/10.1021/jz100115k

33. Krasniqi, F., Zhong, Y.P., Reis, D.A., Scholz, M., Hartmann, R., Hartmann, A., Rolles, D., Rudenko, A., Epp, S.W., Foucar, L., Trigo, M., Fuchs, M., Fritz, D.M., Cammarata, M., Zhu, D., Lemke, H., Braune, M., Ilchen, M., Larsson, J., Techert, S., Strüder, L., Schlichting, I., Ullrich, J.: Resonant X-ray emission spectroscopy with free- electron lasers: nonequilibrium electron dynamics in highly excited polar semiconductors. In: Research in Optical Sciences. OSA (2012). https://doi.org/10.1364/icusd.2012.iw1d.2

34. Kubiček, K., Veedu, S.T., Storozhuk, D., Kia, R., Techert, S.: Geometric and electronic properties in a series of phosphorescent heteroleptic cu(i) complexes: crystallographic and computational studies. Polyhedron 124, 166-176 (2017). https://doi.org/10.1016/j.poly.2016.12. 035

35. Lindenberg, A.M., Larsson, J., Sokolowski-Tinten, K., Gaffney, K., Blome, C., Synnergren, O., Sheppard, J., Caleman, C., MacPhee, A.G., Weinstein, D., Lowney, D.P., Allison, T., Matthews, T., Falcone, R.W., Cavalieri, A.L., Fritz, D.M., Lee, S.H., Bucksbaum, P.H., Reis, D.A., Rudati, J., Mills, D.M., Fuoss, P.H., Stephenson, G.B., Kao, C.C., Siddons, D.P., Pahl, R., Als-Nielsen, J., Dusterer, S., Ischebeck, R., Schlarb, H., Shulte-Schrepping, H., Tschentscher, T., Schneider, J., Hignette, O., Sette, F., Chapman, H.N., Lee, R.W., Hansen, T.N., Techert, S., Wark, J.S., Bergh, M., Huldt, G., van der Spoel, D., Timneanu, M., Hajdu, J., von der Linde, D., Akre, R.A., Bong, E., Emma, P., Krejcik, P., Arthur, J., Brennan, S., Luening, K., Hastings, J.B.: Atomic-scale visualization of inertial dynamics. Science 308(5720), 392-395 (2005). https://doi.org/10.1126/science.1107996

36. Messerschmidt, M., Tschentscher, T., Cammarata, M., Meents, A., Sager, C., Davaasambuu, J., Busse, G., Techert, S.: Ultrafast potential energy surface softening of one-dimensional organic conductors revealed by picosecond time-resolved laue crystallography. J. Phys. Chem. A 114(29), 7677-7681 (2010). https://doi.org/10.1021/jp104081b

37. More, R.: Untersuchung zur strukturdynamik organischer molekularer halbleiter: Photochemische festkörperreaktionen - protonentransfer in carbonsäuredimeren (2012)

38. Moré, R., Busse, G., Hallmann, J., Paulmann, C., Scholz, M., Techert, S.: Photodimerization of crystalline 9-anthracenecarboxylic acid: a nontopotactic autocatalytic transformation. he J. Phys. Chem. C 114(9), 4142-4148 (2010). https://doi.org/10.1021/jp909513v

39. Moré, R., Scholz, M., Busse, G., Busse, L., Paulmann, C., Tolkiehn, M., Techert, S.: Hydrogen bond dynamics in crystalline $\beta$-9-anthracene carboxylic acid-a combined crystallographic and spectroscopic study. Phys. Chem. Chem. Phys. 14(29), 10,187 (2012). https://doi.org/10. 1039/c2cp40216e

40. Neutze, R., Techert, S.: Watching ultrafast chemistry with FEL radiation. TESLA Tech. Des. Rep.-Part I, (2001)

41. Quevedo, W., Busse, G., Hallmann, J., Moré, R., Petri, M., Krasniqi, F., Rudenko, A., Tschentscher, T., Stojanovic, N., Düsterer, S., Treusch, R., Tolkiehn, M., Techert, S., Rajkovic, I.: Ultrafast time dynamics studies of periodic lattices with free electron laser radiation. J. Appl. Phys. 112(9), 093,519 (2012). https://doi.org/10.1063/1.4764918

42. Rajkovic, I., Busse, G., Hallmann, J., Moré, R., Petri, M., Quevedo, W., Krasniqi, F., Rudenko, A., Tschentscher, T., Stojanovic, N., Düsterer, S., Treusch, R., Tolkiehn, M., Techert, S.: Diffraction properties of periodic lattices under free electron laser radiation. Phys. Rev. Lett. 104(12) (2010). https://doi.org/10.1103/physrevlett.104.125503

43. Scholz, M.: Ultrafast X-ray diffraction of metalloorganic compounds (2010) 
44. Schotte, F., Techert, S., Anfinrud, P., Srajer, V., Moffat, K., Wulff, M.: Recent advantages in the generation of pulsed synchrotron radiation suitable for picosecond time-resolved X-ray studies. Wiley-Interscience (2002)

45. Sørensen, H.O., Schmidt, S., Wright, J.P., Vaughan, G.B.M., Techert, S., Garman, E.F., Oddershede, J., Davaasambuu, J., Paithankar, K.S., Gundlach, C., Poulsen, H.F.: Multigrain crystallography. Zeitschrift für Kristallographie 227(1), 63-78 (2012). https://doi.org/10.1524/ zkri.2012.1438

46. Techert, S.: Current developments in time-resolved X-ray diffraction. Crystallogr. Rev. 12(1), 25-45 (2006). https://doi.org/10.1080/08893110600688873

47. Techert, S.: Watching chemistry with femtosecond X-rays, scientific case of an energy recovery linac (2006)

48. Techert, S.: Structural changes during the photoswitching of matter. MPIbpC News 10, 1-8 (2007)

49. Techert, S.: Ultrafast photochemistry. In: Tschentscher, T., Rousse, A. (eds.) Conference Proceedings on X-ray Investigations of Ultrafast Processes, pp. 410-445. Hasylab at DESY, Hamburg (2007)

50. Techert, S.: Concepts of structural dynamics investigations in chemical research, pp. 129-139. Springer Netherlands (2014)

51. Techert, S., Zachariasse, K.A.: Structure determination of the intramolecular charge transfer state in crystalline 4-(diisopropylamino)benzonitrile from picosecond X-ray diffraction. J. Am. Chem. Soc. 126(17), 5593-5600 (2004). https://doi.org/10.1021/ja0379518

52. Veedu, S.T., Cao, D., Lavy, T., Botoshansky, M., Kaftory, M.: Unexpected molecular flip in solid-state photodimerization. Cryst. Growth \& Des. 13(2), 936-941 (2013). https://doi.org/ $10.1021 / \mathrm{cg} 3016707$

53. Grossmann, P., Rajkovic, I., Moré, R., Norpoth, J., Techert, S., Jooss, C., Mann, K.: Timeresolved near-edge $\mathrm{X}$-ray absorption fine structure spectroscopy on photo-induced phase transitions using a tabletop soft-X-ray spectrometer. Rev. Sci. Instrum. 83(5), 053,110 (2012). https://doi.org/10.1063/1.4718936

54. Idzik, K.R., Cywiński, P.J., Kuznik, W., Frydel, J., Licha, T., Ratajczyk, T.: The optical properties and quantum chemical calculations of thienyl and furyl derivatives of pyrene. Phys. Chem. Chem. Phys. 17(35), 22758-22769 (2015). https://doi.org/10.1039/c5cp03013g

55. Mildner, S., Hoffmann, J., Blöchl, P.E., Techert, S., Jooss, C.: Temperature- and dopingdependent optical absorption in the small-polaron systemPr1-xCaxMnO3. Phys. Rev. B 92(3) (2015). https://doi.org/10.1103/physrevb.92.035145

56. Petri, M.: Private communication (2016)

57. Raiser, D.: Development of ultrafast optical methods for the study of the structural dynamics of complex solids (2017)

58. Raiser, D., Mildner, S., Ifland, B., Sotoudeh, M., Blöchl, P., Techert, S., Jooss, C.: Evolution of hot polaron states with a nanosecond lifetime in a manganite perovskite. Adv. Energy Mater. 7(12), 1602,174 (2017). https://doi.org/10.1002/aenm.201602174

59. Veedu, S.T., Raiser, D., Kia, R., Scholz, M., Techert, S.: Ultrafast dynamical study of pyrene$\mathrm{n}, \mathrm{n}$-dimethylaniline (PyDMA) as an organic molecular diode in solid state. J. Phys. Chem. B 118(12), 3291-3297 (2014). https://doi.org/10.1021/jp4121222

60. David, C., Rösner, B., Döring, F., Guzenko, V., Koch, F., Lebugle, M., Marschall, F., Seniutinas, G., Raabe, J., Watts, B., Grolimund, D., Yin, Z., Beye, M., Techert, S., Viefhaus, J., Falkenberg, G., Schroer, C.: Diffractive X-ray optics for synchrotrons and free-electron lasers. Microsc. Microanal. 24(S2), 268-269 (2018). https://doi.org/10.1017/s1431927618013673

61. Döring, F., Marschall, F., Yin, Z., Rosner, B., Beye, M., Miedema, P., Kubicek, K., Glaser, L., Raiser, D., Soltau, J., Guzenko, V.A., Viefhaus, J., Buck, J., Risch, M., Techert, S., David, C.: ID-full field microscopy of elastic and inelastic scattering with transmission off-axis fresnel zone plates. Microsc. Microanal. 24(S2), 184-185 (2018). https://doi.org/10.1017/ s1431927618013260

62. Hallmann, J., Grübel, S., Rajkovic, I., Quevedo, W., Busse, G., Scholz, M., More, R., Petri, M., Techert, S.: First steps towards probing chemical systems and dynamics with free-electron 
laser radiation—case studies at the FLASH facility. J. Phys. B: At. Mol. Opt. Phys. 43(19), 194,009 (2010). https://doi.org/10.1088/0953-4075/43/19/194009

63. Kunnus, K., Rajkovic, I., Schreck, S., Quevedo, W., Eckert, S., Beye, M., Suljoti, E., Weniger, C., Kalus, C., Grübel, S., Scholz, M., Nordlund, D., Zhang, W., Hartsock, R.W., Gaffney, K.J., Schlotter, W.F., Turner, J.J., Kennedy, B., Hennies, F., Techert, S., Wernet, P., Föhlisch, A.: A setup for resonant inelastic soft $\mathrm{X}$-ray scattering on liquids at free electron laser light sources. Rev. Sci. Instrum. 83(12), 123,109 (2012). https://doi.org/10.1063/1.4772685

64. Marschall, F., Yin, Z., Rehanek, J., Beye, M., Döring, F., Kubiček, K., Raiser, D., Veedu, S.T., Buck, J., Rothkirch, A., Rösner, B., Guzenko, V.A., Viefhaus, J., David, C., Techert, S.: Transmission zone plates as analyzers for efficient parallel 2d RIXS-mapping. Sci. Rep. 7(1) (2017). https://doi.org/10.1038/s41598-017-09052-0

65. Rajkovic, I., Grübel, S., Quevedo, W., Techert, S.: Ultrafast pump/probe diffraction and spectroscopy experiments with FEL radiation: setup development from the soft to the hard X-rays with the aim of studying chemical processes. In: Tschentscher, T., Cocco, D. (eds.) Advances in X-ray Free-electron Lasers: Radiation Schemes, X-ray Optics, and Instrumentation. SPIE (2011). https://doi.org/10.1117/12.886763

66. Rajkovic, I., Hallmann, J., Grübel, S., More, R., Quevedo, W., Petri, M., Techert, S.: Development of a multipurpose vacuum chamber for serial optical and diffraction experiments with free-electron laser radiation. Rev. Sci. Instrum. 81(4), 045,105 (2010). https://doi.org/ $10.1063 / 1.3327816$

67. Rajkovic, I., Hallmann, J., Grübel, S., More, R., Quevedo, W., Petri, M., Techert, S.: Development of a multipurpose vacuum chamber for serial optical and diffraction experiments with free- electron laser radiation. Virtual J. Ultrafast X-ray Sci. 9(1), 5 (2010). https://doi.org/10. $1063 / 1.3327816$

68. Techert, S.: Choreografie der moleküle—röntgenblitze "filmen" molekulare schalter. MPIbpC News 5, 1-3 (2010)

69. Techert, S.: Capturing the structural dynamics of biomolecules with X-ray photon-in/photonout techniques. MPIbpC News 1, 1-4 (2011)

70. Wernet, P., Kunnus, K., Schreck, S., Quevedo, W., Kurian, R., Techert, S., de Groot, F.M.F., Odelius, M., Föhlisch, A.: Dissecting local atomic and intermolecular interactions of transition-metal ions in solution with selective X-ray spectroscopy. J. Phys. Chem. Lett. 3(23), 3448-3453 (2012). https://doi.org/10.1021/jz301486u

71. Yin, Z.: X-ray spectroscopy of complex chemical systems in liquid phase (2016)

72. Yin, Z., Löchel, H., Rehanek, J., Goy, C., Kalinin, A., Schottelius, A., Trinter, F., Miedema, P., Jain, A., Valerio, J., Busse, P., Lehmkühler, F., Möller, J., Grübel, G., Madsen, A., Viefhaus, J., Grisenti, R.E., Beye, M., Erko, A., Techert, S.: X-ray spectroscopy with variable line spacing based on reflection zone plate optics. Opt. Lett. 43(18), 4390 (2018). https://doi.org/10.1364/ ol.43.004390

73. Yin, Z., Peters, H.B., Hahn, U., Agåker, M., Hage, A., Reininger, R., Siewert, F., Nordgren, J., Viefhaus, J., Techert, S.: A new compact soft X-ray spectrometer for resonant inelastic X-ray scattering studies at PETRA III. Rev. Sci. Instrum. 86(9), 093,109 (2015). https://doi. org/10.1063/1.4930968

74. Yin, Z., Peters, H.B., Hahn, U., Gonschior, J., Mierwaldt, D., Rajkovic, I., Viefhaus, J., Jooss, C., Techert, S.: An endstation for resonant inelastic X-ray scattering studies of solid and liquid samples. J. Synchrotron Radiat. 24(1), 302-306 (2017). https://doi.org/10.1107/ s1600577516016611

75. Yin, Z., Rajković, I., Raiser, D., Scholz, M., Techert, S.: Experimental setup for high resolution X-ray spectroscopy of solids and liquid samples. In: Klisnick, A., Menoni, C.S. (eds.) X-Ray Lasers and Coherent X-Ray Sources: Development and Applications X. SPIE (2013). https:// doi.org/10.1117/12.2023992

76. Yin, Z., Rehanek, J., Löchel, H., Braig, C., Buck, J., Firsov, A., Viefhaus, J., Erko, A., Techert, S.: Highly efficient soft X-ray spectrometer based on a reflection zone plate for resonant inelastic X-ray scattering measurements. Opt. Express 25(10), 10,984 (2017). https://doi.org/ 10.1364/oe.25.010984 
77. Kunnus, K., Josefsson, I., Rajkovic, I., Schreck, S., Quevedo, W., Beye, M., Grübel, S., Scholz, M., Nordlund, D., Zhang, W., Hartsock, R., Gaffney, K.J., Schlotter, W.F., Turner, J.J., Kennedy, B., Hennies, F., Techert, S., Wernet, P., Odelius, M., Föhlisch, A.: Anti-stokes resonant X-ray raman scattering for atom specific and excited state selective dynamics. New J. Phys. 18(10), 103,011 (2016). https://doi.org/10.1088/1367-2630/18/10/103011

78. Kunnus, K., Josefsson, I., Rajkovic, I., Schreck, S., Quevedo, W., Beye, M., Weniger, C., Grübel, S., Scholz, M., Nordlund, D., Zhang, W., Hartsock, R.W., Gaffney, K.J., Schlotter, W.F., Turner, J.J., Kennedy, B., Hennies, F., de Groot, F.M.F., Techert, S., Odelius, M., Wernet, P., Föhlisch, A.: Identification of the dominant photochemical pathways and mechanistic insights to the ultrafast ligand exchange of fe(CO)5 to fe(CO)4etoh. Struct. Dyn. 3(4), 043,204 (2016). https://doi.org/10.1063/1.4941602

79. Wernet, P., Kunnus, K., Josefsson, I., Rajkovic, I., Quevedo, W., Beye, M., Schreck, S., Grübel, S., Scholz, M., Nordlund, D., Zhang, W., Hartsock, R.W., Schlotter, W.F., Turner, J.J., Kennedy, B., Hennies, F., de Groot, F.M.F., Gaffney, K.J., Techert, S., Odelius, M., Föhlisch, A.: Orbital-specific mapping of the ligand exchange dynamics of $\mathrm{fe}(\mathrm{CO}) 5$ in solution. Nature 520(7545), 78-81 (2015). https://doi.org/10.1038/nature14296

80. Yin, Z., Quevedo, W., Rajkovic, I., Wernet, P., Föhlisch, A., Pietsch, A., Techert, S.: Ionic solutions probed by resonant inelastic X-ray scattering. Zeitschrift für Physikalische Chem. 1(1), 100-120 (2015). https://doi.org/10.1515/zpch-2015-0610

81. Debnarova, A.: Ab-initio studies of chemical reactions under intense X-ray radiation (2009)

82. Debnarova, A., Techert, S., Schmatz, S.: Ab initio studies of ultrafast X-ray scattering of the photodissociation of iodine. J. Chem. Phys. 133(12), 124,309 (2010). https://doi.org/10.1063/ 1.3475567

83. Debnarova, A., Techert, S., Schmatz, S.: Computational studies of the X-ray scattering properties of laser aligned stilbene. J. Chem. Phys. 134(5), 054,302 (2011). https://doi.org/10. $1063 / 1.3523569$

84. Kjaer, K.S., Zhang, W., Alonso-Mori, R., Bergmann, U., Chollet, M., Hadt, R.G., Hartsock, R.W., Harlang, T., Kroll, T., Kubicek, K., Lemke, H.T., Liang, H.W., Liu, Y., Nielsen, M.M., Robinson, J.S., Solomon, E.I., Sokaras, D., van Driel, T.B., Weng, T.C., Zhu, D., Persson, P., Warnmark, K., Sundström, V., Gaffney, K.J.: Ligand manipulation of charge transfer excited state relaxation and spin crossover in [fe(2,2/-bipyridine)2(CN)2]. Struct. Dyn. 4(4), 044,030 (2017). https://doi.org/10.1063/1.4985017

85. Neutze, R., Wouts, R., Techert, S., Kirrander, A., Davidson, J., Kocsis, M., Schotte, F., Wulff, M.: Visualising photo-chemical dynamics in solution through picosecond X-ray scattering. Phys. Rev. Lett. 87(4), 195,508-195,512 (2001). https://doi.org/10.1103/PhysRevLett.86. 2030

86. Petrov, N.K., Gulakov, M.N., Alfimov, M.V., Busse, G., Techert, S.: Solvation-shell effect on the cyanine-dye fluorescence in binary liquid mixtures. Zeitschrift für Physikalische Chem. 221(4), 537-547 (2007). https://doi.org/10.1524/zpch.2007.221.4.537

87. Techert, S., Neutze, R.: Ultrafast photochemistry, pp. 133-139. TESLA Technical Design Report (2001)

88. Zhang, W., Kjær, K.S., Alonso-Mori, R., Bergmann, U., Chollet, M., Fredin, L.A., Hadt, R.G., Hartsock, R.W., Harlang, T., Kroll, T., Kubicek, K., Lemke, H.T., Liang, H.W., Liu, Y., Nielsen, M.M., Persson, P., Robinson, J.S., Solomon, E.I., Sun, Z., Sokaras, D., van Driel, T.B., Weng, T.C., Zhu, D., Warnmark, K., Sundstrom, V., Gaffney, K.J.: Tracking excitedstate charge and spin dynamics in iron coordination complexes. Nature 509(7500), 345-348 (2014). https://doi.org/10.1038/nature13252

89. Zhang, W., Kjær, K.S., Alonso-Mori, R., Bergmann, U., Chollet, M., Fredin, L.A., Hadt, R.G., Hartsock, R.W., Harlang, T., Kroll, T., Kubicek, K., Lemke, H.T., Liang, H.W., Liu, Y., Nielsen, M.M., Persson, P., Robinson, J.S., Solomon, E.I., Sun, Z., Sokaras, D., van Driel, T.B., Weng, T.C., Zhu, D., Warnmark, K., Sundstrom, V., Gaffney, K.J.: Manipulating charge transfer excited state relaxation and spin crossover in iron coordination complexes with ligand substitution. Chem. Sci. 8(1), 515-523 (2017). https://doi.org/10.1039/c6sc03070j 
90. Debnarova, A., Techert, S., Schmatz, S.: Limitations of high-intensity soft x-ray laser fields for the characterisation of water chemistry: Coulomb explosion of the octamer water cluster. Phys. Chem. Chem. Phys. 14(27), 9606 (2012). https://doi.org/10.1039/c2cp40598a

91. Jay, R.M., Norell, J., Eckert, S., Hantschmann, M., Beye, M., Kennedy, B., Quevedo, W., Schlotter, W.F., Dakovski, G.L., Minitti, M.P., Hoffmann, M.C., Mitra, A., Moeller, S.P., Nordlund, D., Zhang, W.W.W.L., Kunnus, K., Kubicek, K., Techert, S.A., Lundberg, M., Wernet, P., Gaffney, K., Odelius, M., Föhlisch, A.: Disentangling transient charge density and metal-ligand covalency in photoexcited ferricyanide with femtosecond resonant inelastic soft X-ray scattering. J. Phys. Chem. Lett. 9(12), 3538-3543 (2018). https://doi.org/10.1021/acs. jpclett.8b01429

92. Kunnus, K., Josefsson, I., Schreck, S., Quevedo, W., Miedema, P.S., Techert, S., de Groot, F.M.F., Föhlisch, A., Odelius, M., Wernet, P.: Quantifying covalent interactions with resonant inelastic soft x-ray scattering: case study of Ni2 aqua complex. Chem. Phys. Lett. 669, 196201 (2017). https://doi.org/10.1016/j.cplett.2016.12.046

93. Mitzner, R., Rehanek, J., Kern, J., Gul, S., Hattne, J., Taguchi, T., Alonso-Mori, R., Tran, R., Weniger, C., Schröder, H., Quevedo, W.H.L., Sierra, R.G., Han, G., Lassalle-Kaiser, B., Koroidov, S., Kubicek, K., Schreck, S., Kunnus, K., Brzhezinskaya, M., Firsov, A., Minitti, M.P., Turner, J.J., Moeller, S., Sauter, N.K., Bogan, M.J., Nordlund, D.W.F.S., Messinger, J., Borovik, A., Techert, S., de Groot, F.M.F., Föhlisch, A., Erko, A.U.B., Yachandra, V.K., Wernet, P., Yano, J.: L-edge x-ray absorption spectroscopy of dilute systems relevant to metalloproteins using an x-ray free-electron laser. J. Phys. Chem. Lett. 4(21), 3641-3647 (2013). https://doi.org/10.1021/jz401837f

94. Petri, M.: Time-resolved structure determination in low-periodic systems (2011)

95. Petri, M., Busse, G., Quevedo, W., Techert, S.: Photo-induced phase transitions to liquid crystal phases: influence of the chain length from c8e4 to c14e4. Materials 2(3), 1305-1322 (2009). https://doi.org/10.3390/ma2031305

96. Petri, M., Menzel, A., Bunk, O., Busse, G., Techert, S.: Concentration effects on the dynamics of liquid crystalline self-assembly: time-resolved x-ray scattering studies. J. Phys. Chem. A 115(11), 2176-2183 (2011). https://doi.org/10.1021/jp1108224

97. Quevedo, W.: Time-resolved investigations in liquid crystals and periodic nanostructures (2010)

98. Quevedo, W., Peth, C., Busse, G., Mann, K., Techert, S.: Nanosecond dynamics of photoexcited lyotropic liquid crystal structures. J. Phys. Chem. B 114(26), 8593-8599 (2010). https:// doi.org/10.1021/jp101609q

99. Quevedo, W., Peth, C., Busse, G., Scholz, M., Mann, K., Techert, S.: Time-resolved soft x-ray diffraction reveals transient structural distortions of ternary liquid crystals. Int. J. Mol. Sci. 10(11), 4754-4771 (2009). https://doi.org/10.3390/ijms10114754

100. Quevedo, W., Petri, M., Busse, G., Techert, S.: On the mechanism of photoinduced phase transitions in ternary liquid crystal systems near thermal equilibrium. J. Chem. Phys. 129(2), 024,502 (2008). https://doi.org/10.1063/1.2943200

101. Quevedo, W., Petri, M., Techert, S.: Home-based time-resolved photo small angle x-ray diffraction and its applications. Zeitschrift für Kristallographie 223(4-5/2008) (2008). https:// doi.org/10.1524/zkri.2008.0031

102. Ramos, A.S.F., Techert, S.: Influence of the water structure on the acetylcholinesterase efficiency. Biophys. J. 89(3), 1990-2003 (2005). https://doi.org/10.1529/biophysj.104.055798

103. Ramos, A.S.F., Techert, S.: Determination of the relative permittivity of acetylcholinesterase. J. Phys. Chem. Lett. 1(1), 417-419 (2009). https://doi.org/10.1021/jz900261z

104. Schreck, S., Beye, M., Sellberg, J.A., McQueen, T., Laksmono, H., Kennedy, B., Eckert, S., Schlesinger, D., Nordlund, D., Ogasawara, H., Sierra, R.G., Segtnan, V., Kubicek, K., Schlotter, W.F., Dakovski, G.L., Moeller, S., Bergmann, U., Techert, S., Pettersson, L., Wernet, P., Bogan, M.J., Harada, Y., Nilsson, A., Föhlisch, A.: Reabsorption of soft X-ray emission at high X-ray free-electron laser fluences. Phys. Rev. Lett. 113(15) (2014). https://doi.org/10. 1103/physrevlett.113.153002 
105. Schreck, S., Pietzsch, A., Kennedy, B., Såthe, C., Miedema, P.S., Techert, S., Strocov, V.N., Schmitt, T., Hennies, F., Rubensson, J.E., Föhlisch, A.: Ground state potential energy surfaces around selected atoms from resonant inelastic X-ray scattering. Sci. Rep. 7, 20,054 (2016). https://doi.org/10.1038/srep20054

106. Sellberg, J.A., McQueen, T.A., Laksmono, H., Schreck, S., Beye, M., DePonte, D.P., Kennedy, B., Nordlund, D., Sierra, R.G., Schlesinger, D., Tokushima, T., Zhovtobriukh, I., Eckert, S., Segtnan, V.H., Ogasawara, H., Kubicek, K., Techert, S., Bergmann, U., Dakovski, G.L., Schlotter, W.F., Harada, Y., Bogan, M.J., Wernet, P., Föhlisch, A., Pettersson, L.G.M., Nilsson, A.: X-ray emission spectroscopy of bulk liquid water in "no-man's land". J. Chem. Phys. 142(4), 044,505 (2015). https://doi.org/10.1063/1.4905603

107. Yin, Z., Inhester, L., Veedu, S.T., Quevedo, W., Pietzsch, A., Wernet, P., Groenhof, G., Föhlisch, A., Grubmüller, H., Techert, S.: Cationic and anionic impact on the electronic structure of liquid water. J. Phys. Chem. Lett. 8(16), 3759-3764 (2017). https://doi.org/10.1021/acs. jpclett.7b01392

108. Yin, Z., Rajkovic, I., Kubicek, K., Quevedo, W., Pietzsch, A., Wernet, P., Föhlisch, A., Techert, S.: Probing the hofmeister effect with ultrafast core-hole spectroscopy. J. Phys. Chem. B 118(31), 9398-9403 (2014). https://doi.org/10.1021/jp504577a

109. (a) Fenn, J.B.: Angew. Chem. Int. Ed. Engl. 42, 3871 (2003). (b) Bari, S., Gonzalez-Magaña, O., Reitsma, G., Werner, J., Schippers, S., Hoekstra, R., Schlathölter, T.: J. Chem. Phys. 134, 024314 (2011). (c) Milosavljević, A.R., Nicolas, C., Lemaire, J., Dehon, C., Thissen, R., Bizau, J.-M., Réfrégiers, M., Nahon, L., Giuliani, A.: Phys. Chem. Chem. Phys. 13, 15432 (2011). (d) Schwob, L., Lalande, M., Egorov, D., Rangama, J., Hoekstra, R., Vizcaino, V., Schlathölter, T., Poully, J.-C.: Phys. Chem. Chem. Phys. 22895 (2017)

110. Arnlund, D., Johansson, L.C., Wickstrand, C., Barty, A., Williams, G.J., Malmerberg, E., Davidsson, J., Milathianaki, D., DePonte, D.P., Shoeman, R.L., Wang, D., James, D., Katona, G., Westenhoff, S., White, T.A., Aquila, A., Bari, S., Berntsen, P., Bogan, M., van Driel, T.B., Doak, R.B., Kjær, K.S., Frank, M., Fromme, R.I.G., Henning, R., Hunter, M.S., Kirian, R.A., Kosheleva, I., Kupitz, C., Liang, M., Martin, A.V., Nielsen, M.M., Messerschmidt, M., Seibert, M.M.J.S., Stellato, F., Weierstall, U., Zatsepin, N.A., Spence, J.C.H., Fromme, P., Schlichting, I., Boutet, S., Groenhof, G., Chapman, H.N., Neutze, R.: Visualizing a protein quake with time-resolved X-ray scattering at a free-electron laser. Nat. Methods 11(9), 923-926 (2014). https://doi.org/10.1038/nmeth.3067

111. Bari, S., Egorov, D., Jansen, T.L.C., Boll, R., Hoekstra, R., Techert, S., Zamudio-Bayer, V., Bülow, C., Lindblad, R., Leistner, G., Lawicki, A., Hirsch, K., Miedema, P.S., von Issendorff, B., Lau, T., Schlathölter, T.: Soft X-ray spectroscopy as a probe for gas-phase protein structure: electron impact ionization from within. Chem.-A Eur. J. 24(30), 7631-7636 (2018). https:// doi.org/10.1002/chem.201801440

112. Bari, S., González-Magaña, O., Reitsma, G., Werner, J., Schippers, S., Hoekstra, R., Schlathölter, T.: Photodissociation of protonated leucine-enkephalin in the VUV range of 8-40 eV. J. Chem. Phys. 134(2), 024,314 (2011). https://doi.org/10.1063/1.3515301

113. Egorov, D., Bari, S., Boll, R., Dörner, S., Deinert, S., Techert, S., Hoekstra, R., ZamudioBayer, V., Lindblad, R., Bülow, C., Timm, M., von Issendorff, B., Lau, T., Schlathölter, T.: Near-edge soft X-ray absorption mass spectrometry of protonated melittin. J. Am. Soc. Mass Spectrom. 29(11), 2138-2151 (2018). https://doi.org/10.1007/s13361-018-2035-6

114. González-Magaña, O., Tiemens, M., Reitsma, G., Boschman, L., Door, M., Bari, S., Lahaie, P.O., Wagner, J.R., Huels, M.A., Hoekstra, R., Schlathölter, T.: Fragmentation of protonated oligonucleotides by energetic photons and cq+ions. Phys. Rev. A 87(3) (2013). https://doi. org/10.1103/physreva.87.032702

115. Jain, R., Petri, M., Kirschbaum, S., Feindt, H., Steltenkamp, S., Sonnenkalb, S., Becker, S., Griesinger, C., Menzel, A., Burg, T.P., Techert, S.: X-ray scattering experiments with highflux X-ray source coupled rapid mixing microchannel device and their potential for high-flux neutron scattering investigations. Eur. Phys. J. E 36(9) (2013). https://doi.org/10.1140/epje/ i2013-13109-9 
116. Jain, R., Techert, S.: Time-resolved and in-situ X-ray scattering methods beyond photoactivation: utilizing high-flux X-ray sources for the study of ubiquitous nonphotoactive proteins. Protein \& Pept. Lett. 23(3), 242-254 (2016). https://doi.org/10.2174/ 0929866523666160106153847

117. Kupitz, C., Basu, S., Grotjohann, I., Fromme, R., Zatsepin, A.N., Rendek, K.N., Hunter, M.S., Shoeman, R.L., White, T.A., Wang, D., James, D., Yang, J.H., Cobb, D.E., Reeder, B., Sierra, R.G., Liu, H., Barty, A., Aquila, A.L., Deponte, D., Kirian, R.A., Bari, S., Bergkamp, J.J., Beyerlein, K.R., Bogan, M.J., Caleman, C., Chao, T.C., Conrad, C.E., Davis, K.M., Fleckenstein, H., Galli, L., Hau-Riege, S.P., Kassemeyer, S., Laksmono, H.M.L., Lomb, L.S.M., Martin, A.V., Messerschmidt, M., Milathianaki, D., Nass, K., Ros, A., Roy-Chowdhury, S., Schmidt, K., Seibert, M., Steinbrener, J., Stellato, F., Yan, L., Yoon, C., Moore, T.A., Moore, A.L., Pushkar, Y., Williams, G.J., Boutet, S., Doak, R.B., Weierstall, U., Frank, M.H.N.C., Spence, J.C.H., Fromme, P.: Serial time-resolved crystallography of photosystem II using a femtosecond X-ray laser. Nature 513(7517), 261-265 (2014). https://doi.org/10.1038/nature13453

118. Petri, M., Frey, S., Menzel, A., Görlich, D., Techert, S.: Structural characterization of nanoscale meshworks within a nucleoporin FG hydrogel. Biomacromolecules 13(6), 18821889 (2012). https://doi.org/10.1021/bm300412q

119. Schlathölter, T., Reitsma, G., Egorov, D., González-Magaña, O., Bari, S., Boschman, L., Bodewits, E., Schnorr, K., Schmid, G., Schröter, C.D., Moshammer, R., Hoekstra, R.: Multiple ionization of free ubiquitin molecular ions in extreme ultraviolet free-electron laser pulses. Angew. Chem. Int. Edition 55(36), 10741-10745 (2016). https://doi.org/10.1002/ anie. 201605335

120. Schulz, J., Bari, S., Buck, J., Uetrecht, C.: Sample refreshment schemes for high repetition rate FEL experiments. In: Tschentscher, T. Tiedtke, K. (eds.) Advances in X-ray Free-Electron Lasers II: Instrumentation. SPIE (2013). https://doi.org/10.1117/12.2019754

121. Techert, F., Techert, S., Woo, L., Beck, W., Lebsanft, H., Wizemann, V.: High blood flow rates with adjustment of needle diameter do not increase hemolysis during hemodialysis treatment. J. Vasc. Access 8(4), 252-257 (2007). https://doi.org/10.1177/112972980700800406

122. Boll, R., Anielski, D., Bostedt, C., Bozek, J.D., Christensen, L., Coffee, R., De, S., Decleva, P., Epp, S.W., Erk, B., Foucar, L., Krasniqi, F., Küpper, J., Rouzée, A., Rudek, B., Rudenko, A., Schorb, S., Stapelfeldt, H., Stener, M., Stern, S., Techert, S., Trippel, S., Vrakking, M.J.J., Ullrich, J., Rolles, D.: Femtosecond photoelectron diffraction on laser-aligned molecules: towards time-resolved imaging of molecular structure. Phys. Rev. A 88(6) (2013). https://doi. org/10.1103/physreva.88.061402

123. Bomme, C., Anielski, D., Savelyev, E., Boll, R., Erk, B., Bari, S., Viefhaus, J., Stener, M., Decleva, P., Rolles, D.: Diffraction effects in the recoil-frame photoelectron angular distributions of halomethanes. J. Phys.: Conf. Ser. 635(11), 112,020 (2015). https://doi.org/10.1088/ $1742-6596 / 635 / 11 / 112020$

124. Erk, B., Müller, J.P., Bomme, C., Boll, R., Brenner, G., Chapman, H.N., Correa, J., Düsterer, S., Dziarzhytski, S., Eisebitt, S., Graafsma, H., Grunewald, S., Gumprecht, L., Hartmann, R., Hauser, G., Keitel, B., von Korff Schmising, C., Kuhlmann, M., Manschwetus, B., Mercadier, L., Müller, E., Passow, C., Plönjes, E., Ramm, D., Rompotis, D., Rudenko, A., Rupp, D., Sauppe, M., Siewert, F., Schlosser, D., Strüder, L., Swiderski, A., Techert, S., Tiedtke, K., Tilp, T., Treusch, R., Schlichting, I., Ullrich, J., Moshammer, R., Möller, T., Rolles, D.: CAMP@FLASH: an end-station for imaging, electron- and ion-spectroscopy, and pumpprobe experiments at the FLASH free-electron laser. J. Synchrotron Radiat. 25(5), 1529-1540 (2018). https://doi.org/10.1107/s1600577518008585

125. Foucar, L., Barty, A., Coppola, N., Hartmann, R., Holl, P., Hoppe, U., Kassemeyer, S., Kimmel, N., Küpper, J., Scholz, M., Techert, S., White, T.A., Strüder, L., Ullrich, J.: CASS-CFELASG software suite. Comput. Phys. Commun. 183(10), 2207-2213 (2012). https://doi.org/ 10.1016/j.cpc.2012.04.023

126. Savelyev, E., Boll, R., Bomme, C., Schirmel, N., Redlin, H., Erk, B., Düsterer, S., Müller, E., Höppner, H., Toleikis, S., Müller, J., Czwalinna, M.K., Treusch, R., Kierspel, T., Mullins, T., Trippel, S., Wiese, J., Küpper, J., Brauße, F., Krecinic, F., Rouzee, A., Rudawski, P., Johnsson, 
P., Amini, K., Lauer, A., Burt, M., Brouard, M., Christensen, L., Thørgersen, J., Stapelfeldt, H., Berrah, N., Müller, M., Ulmer, A., Techert, S., Rudenko, A., Rolles, D.: Jitter-correction for IR/UV-XUV pump-probe experiments at the FLASH free-electron laser. New J. Phys. 19(4), 043,009 (2017). https://doi.org/10.1088/1367-2630/aa652d

127. Strueder, L., Epp, S., Rolles, D., Hartmann, R., Holl, P., Lutz, G., Soltau, H., Eckart, R., Reich, C., Heinzinger, K., Thamm, C., Rudenko, A., Krasniqi, F., Techert, S., Mosshammer, R., Kühnel, K.U., Bauer, C., Schröter, C.D., Miessner, D., Porro, M., Hälker, O., Meidinger, N., Ziegler, N., Hermann, S., Pietsch, U., Walenta, A., Leitenberger, W., Boestedt, C., Möller, T., Rupp, D.M.A., Graafsma, H., Hirsemann, H., Gärtner, K., Richter, R., Foucar, L., Shoeman, R.L., Schlichting, I., Ullrich, J.: Large-format, high-speed, X-ray pnCCDs combined with electron and ion imaging spectrometers in a multipurpose chamber for experiments at 4 th generation light sources. Nucl. Instrum. Methods Phys. Res. Sect. A: Accel. Spectrom. Detect. Assoc. Equip. 614(3), 483-496 (2010). https://doi.org/10.1016/j.nima.2009.12.053

128. Ablikim, U., Bomme, C., Xiong, H., Savelyev, E., Obaid, R., Kaderiya, B., Augustin, S., Schnorr, K., Dumitriu, I., Osipov, T., Bilodeau, R., Kilcoyne, D., Kumarappan, V., Rudenko, A., Berrah, N., Rolles, D.: Identification of absolute geometries of cis and trans molecular isomers by coulomb rxplosion imaging. Sci. Rep. 6(1), 433 (2016). https://doi.org/10.1038/ srep38202

129. Anielski, D., Boll, R., Rolles, D.: Time-resolved photoelectron diffraction on laser-aligned molecules. In: Research in Optical Sciences. OSA (2012). https://doi.org/10.1364/hilas.2012. jt2a.38

130. Gomez, L.F., Ferguson, K.R., Cryan, J.P., Bacellar, C., Tanyag, R.M.P., Jones, C., Schorb, S., Anielski, D., Belkacem, A., Bernando, C., Boll, R., Bozek, J., Carron, S., Chen, G., Delmas, T., Englert, L., Epp, S.W., Erk, B., Foucar, L., Hartmann, R., Hexemer, A., Huth, M., Kwok, J., Leone, S.R., Ma, J.H.S., Maia, F.R.N.C., Malmerberg, E., Marchesini, S., Neumark, D.M., Poon, B., Prell, J., Rolles, D., Rudek, B., Rudenko, A., Seifrid, M., Siefermann, K.R., Sturm, F.P., Swiggers, M., Ullrich, J., Weise, F., Zwart, P., Bostedt, C., Gessner, O., Vilesov, A.F.: Shapes and vorticities of superfluid helium nanodroplets. Science 345(6199), 906-909 (2014). https://doi.org/10.1126/science.1252395

131. Gorkhover, T., Schorb, S., Coffee, R., Adolph, M., Foucar, L., Rupp, D., Aquila, A., Bozek, J.D., Epp, S.W., Erk, B., Gumprecht, L., Holmegaard, L., Hartmann, A., Hartmann, R.G.H., Holl, P., Hömke, A., Johnsson, P., Kimmel, N., Kühnel, K.U., Messerschmidt, M., Reich, C., Rouzée, A., Rudek, B., Schmidt, C., Schulz, J., Soltau, H., Stern, S., Weidenspointner, G., White, B., Küpper, J., Strüder, L., Schlichting, I., Ullrich, J., Rolles, D., Rudenko, A., Möller, T., Bostedt, C.: Femtosecond and nanometre visualization of structural dynamics in superheated nanoparticles. Nat. Photonics 10(2), 93-97 (2016). https://doi.org/10.1038/ nphoton.2015.264

132. Hädrich, S., Rothhardt, J., Klas, R., Tschernajew, M., Hoffmann, A., Tadesse, G.K., Klenke, A., Gottschall, T., Eidam, T., Limpert, J., Tünnermann, A., Boll, R., Bomme, C., Dachraoui, H., Erk, B., Fraia, M.D., Horke, D., Kierspel, T., Mullins, T., A. Przystawik, E.S., Wiese, J., Laarmann, T.J.K., Rolles, D., Barkowski, M., Sadashivaiah, S., Urbancic, J., Aeschlimann, M., Mathias, S.: High photon flux $70 \mathrm{eV} \mathrm{HHG} \mathrm{source} \mathrm{for} \mathrm{applications} \mathrm{in} \mathrm{molecular} \mathrm{and} \mathrm{solid}$ state physics. In: High-brightness Sources and Light-Driven Interactions. OSA (2016). https:// doi.org/10.1364/hilas.2016.ht1b.2

133. Hau-Riege, S.P., Graf, A., Döppner, T., London, R.A., Krzywinski, J., Fortmann, C., Glenzer, S.H., Frank, M., Sokolowski-Tinten, K., Messerschmidt, M., Bostedt, C., Schorb, S., Bradley, J.A., Lutman, A., Rolles, D., Rudenko, A., Rudek, B.: Ultrafast transitions from solid to liquid and plasma states of graphite induced by X-ray free-electron laser pulses. Phys. Rev. Lett. 108(21) (2012). https://doi.org/10.1103/physrevlett.108.217402

134. Jones, C.F., Bernando, C., Tanyag, R.M.P., Bacellar, C., Ferguson, K.R., Gomez, F., Anielski, D., Belkacem, A., Boll, R., Bozek, J., Carron, S., Cryan, J., Englert, L., Epp, W., Erk, B., Foucar, L., Hartmann, R.D.M.N., Rolles, D., Rudenko, A., Siefermann, K.R., Weise, F., Rudek, B., Sturm, F.P., Ullrich, J., Bostedt, C., Gessner, O., Vilesov, A.F.: Coupled motion of 
xe clusters and quantum vortices in he nanodroplets. Phys. Rev. B 93(18), 180,510 (2016). https://doi.org/10.1103/physrevb.93.180510

135. Kierspel, T., Wiese, J., Mullins, T., Robinson, J., Aquila, A., Barty, A., Bean, R., Boll, R., Boutet, S., Bucksbaum, P.H., Chapman, H.N., Christensen, L.A.F., Hunter, M., Koglin, J.E., Liang, M., Mariani, V., Morgan, A.A.N., Petrovic, V., Rolles, D.A.R., Schnorr, K., Stapelfeldt, H., Stern, S., Thogersen, J., Yoon, C.H., Wang, F., Trippel, S., Küpper, J.: Strongly aligned gas-phase molecules at free-electron lasers. J. Phys. B: Atom. Mol. Opt. Phys. 48(20), 204,002 (2015). https://doi.org/10.1088/0953-4075/48/20/204002

136. Liekhus-Schmaltz, C., Tenney, I., Osipov, T., Bucksbaum, P.H., Petrovic, V.S., Belkacem, A., Berrah, N., Boll, R., Bomme, C., Bostedt, C., Bozek, J.D., Carron, S., Coffee, R.N., Devin, J., Erk, B., Fang, L., Field, R.W., Ferguson, K., Foucar, L., Frasinski, L.J., Glownia, J.M., Guehr, M., Kamalov, A., Krzywinski, J., Li, H., Marangos, J.P., Martinez, T., McFarland, B.K., Miyabe, S., Murphy, B.F., Natan, A.A., Rolles, D., Rudenko, A., Sanchez, A., Siano, M., Simpson, E., Spector, L.S., Swiggers, M.L., Walke, D.J., Wang, S., Weber, T.: Mapping the fragmentation of acetylene with femtosecond resolution pump probe at LCLS using 2, 3, and 4 particle coincidences. In: CLEO: 2014. OSA (2014). https://doi.org/10.1364/cleo_at. 2014.jth2a.88

137. Liekhus-Schmaltz, C., Tenney, I., Osipov, T., Sanchez-Gonzalez, A., Berrah, N., Boll, R., Bomme, C., Bostedt, C., Bozek, J.D., Carron, S., Coffee, R.N., Devin, J., Erk, B., Ferguson, K.R., Field, R.W.L.F., Frasinski, L.J., Glownia, J.M., Guehr, M., Kamalov, A., Krzywinski, J., Li, H., Marangos, J.P., Martinez, T., McFarland, B.K., Miyabe, S., Murphy, B.F., Natan, A.A., Rolles, D., Rudenko, A., Siano, M., Simpson, E.R., Spector, L., Swiggersa, M., Walke, D.S., Weber, T., Bucksbaum, P.H., Petrovic, V.S.: Ultrafast isomerization initiated by X-ray core ionization. Nat. Commun. 6(1) (2015). https://doi.org/10.1038/ncomms9199

138. Rolles, D., Boll, R., Erk, B., Rompotis, D., Manschwetus, B.: An experimental protocol for femtosecond nir/uv-xuv pump-probe experiments with free-electron lasers. JoVE 140(e57055) (2018). https://doi.org/10.3791/57055

139. Rolles, D., Boll, R., Tamrakar, S.R., Anielski, D., Bomme, C.: Femtosecond photoelectron diffraction: a new approach to image molecular structure during photochemical reactions. In: Liu, Z. (ed.) Ultrafast Nonlinear Imaging and Spectroscopy II. SPIE (2014). https://doi.org/ $10.1117 / 12.2061783$

140. Rothhardt, J., Hädrich, S., Shamir, Y., Tschnernajew, M.R.K., Hoffmann, A., Tadesse, G.K., Klenke, A., Gottschall, T., Eidam, T., Limpert, J., Tünnermann, A., Boll, R., Bomme, C., Dachraoui, H., Erk, B., Fraia, M.D., Horke, D.A., Kierspel, T., Mullins, T.A.P., Savelyev, E., Wiese, J.T.L., Küpper, J., Rolles, D.: High-repetition-rate and high-photon-flux $70 \mathrm{eV}$ highharmonic source for coincidence ion imaging of gas-phase molecules. Opt. Express 24(16), 18,133 (2016). https://doi.org/10.1364/oe.24.018133

141. Rudek, B., Son, S.K., Foucar, L., Epp, S.W., Erk, B., Hartmann, R., Adolph, M., Andritschke, R., Aquila, A., Berrah, N., Bostedt, C., Bozek, J., Coppola, N., Filsinger, F., Gorke, H., Gorkhover, T., Graafsma, H., Gumprecht, L., Hartmann, A., Hauser, G., Herrmann, S., Hirsemann, H., Holl, P., Hömke, A., Journel, L., Kaiser, C., Kimmel, N., Krasniqi, F., Kühnel, K.U., Matysek, M., Messerschmidt, M., Miesner, D., Möller, T., Moshammer, R., Nagaya, K., Nilsson, B., Potdevin, G., Pietschner, D., Reich, C., Rupp, D., Schaller, G., Schlichting, I., Schmidt, C.F.S., Schorb, S., Schröter, C., Schulz, J., Simon, M., Soltau, H., Strüder, L., Ueda, K., Weidenspointner, G., Santra, R., Ullrich, J., Rudenko, A., Rolles, D.: Ultra-efficient ionization of heavy atoms by intense X-ray free-electron laser pulses. Nat. Photonics 6(12), 858-865 (2012). https://doi.org/10.1038/nphoton.2012.261

142. Rudenko, A., Rolles, D.: Time-resolved studies with fels. J. Electron Spectrosc. Relat. Phenom. 204, 228 (2015). https://doi.org/10.1016/j.elspec.2015.07.010

143. Sauppe, M., Rompotis, D., Erk, B., Bari, S., Bischoff, T., Boll, R., Bomme, C., Bostedt, C., Dörner, S., Düsterer, S., Feigl, T., Flückiger, L., Gorkhover, T., Kolatzki, K., Langbehn, B., Monserud, N., Mueller, E., Müller, J.P., Passow, C., Ramm, D., Rolles, D., Schubert, K., Schwob, L., Senfftleben, B., Treusch, R., Ulmer, A., Weigelt, H., Zimbalsko, J., Zimmermann, J., Moeller, T., Rupp, D.: XUV double-pulses with femtosecond to 650 ps separation from a 
multilayer-mirror-based split-and-delay unit at FLASH. J. Synchrotron Radiat. 25(5), 15171528 (2018). https://doi.org/10.1107/s1600577518006094

144. Schippers, S., Buhr, T., Mueller, A., Perry-Sassmannshausen, A., Ricz, S., Klumpp, S., Mertens, K., Reinwardt, S., Martins, M., Schubert, K., Bari, S., Waitz, F.M., Jahnke, T., Schöffler, M., Dörner, R.: Pipe: The photon-ion-endstation at petra iii for experimental studies of xuv-photoprocesses in small quantum systems. In: Deutsche Tagung für Forschung mit Synchrotronstrahlung, Neutronen und Ionenstrahlen an Großgeräten (2018)

145. Schippers, S., Martins, M., Beerwerth, R., Bari, S., Holste, K., Schubert, K., Viefhaus, J., Savin, D.W., Fritzsche, S., Mueller, A.: Near l-edge single and multiple photoionization of singly charged iron ions. Astrophys. J. 849(1), 5 (2017). https://doi.org/10.3847/1538-4357/ aa8fcc

146. Schnorr, K., Senftleben, A., Kurka, M., Rudenko, A., Foucar, L., Schmid, G., Broska, A., Pfeifer, T., Meyer, K., Anielski, D., Boll, R., Rolles, D., Kübel, M., Kling, M.F., Jiang, Y.H., Mondal, S., Tachibana, T., Ueda, K., Marchenko, T., Simon, M., Brenner, G., Treusch, R., Scheit, S., Averbukh, V., Ullrich, J., Schröter, C.D., Moshammer, R.: Time-resolved measurement of interatomic coulombic decay in $\mathrm{Ne}_{2}$. Phys. Rev. Lett. 111(9) (2013). https://doi.org/ 10.1103/physrevlett.111.093402

147. Schnorr, K., Senftleben, A., Schmid, G., Augustin, S., Kurka, M., Rudenko, A., Foucar, L., Broska, A., Meyer, K., Anielski, D., Boll, R., Rolles, D., Kübel, M., Kling, M.F., Jiang, Y.H., Mondal, S., Tachibana, T., Ueda, K., Marchenko, T., Simon, M., Brenner, G., Treusch, R., Scheit, S., Averbukh, V., Ullrich, J., Pfeifer, T., Schröter, C.D., Moshammer, R.: Time-resolved study of ICD in ne dimers using FEL radiation. J. Electron Spectros. Relat. Phenom. 204, 245-256 (2015). https://doi.org/10.1016/j.elspec.2015.07.009

148. Schorb, S., Gorkhover, T., Cryan, J.P., Glownia, J.M., Bionta, M.R., Coffee, R.N., Erk, B., Boll, R., Schmidt, C., Rolles, D., Rudenko, A., Rouzee, A., Swiggers, M., Carron, S., Castagna, J.C., Bozek, J.D., Messerschmidt, M., Schlotter, W.F., Bostedt, C.: X-ray-optical cross-correlator for gas-phase experiments at the linac coherent light source free-electron laser. Appl. Phys. Lett. 100(12), 121,107 (2012). https://doi.org/10.1063/1.3695163

149. Tanyag, R., Bernando, C., Jones, C.F., Bacellar, C., Ferguson, K.R., Anielski, D., Boll, R., Carron, S.J.P.C., Englert, L., Epp, S.W., Erk, B., Foucar, L., Gomez, L.F.R.H., Neumark, D.M., Rolles, D.B.R., Rudenko, A., Siefermann, K.R., Ullrich, J., Weise, F., Bostedt, C., Gessner, O., Vilesov, A.F.: Communication: X-ray coherent diffractive imaging by immersion in nanodroplets. Struct. Dyn. 2(5), 051,102 (2015). https://doi.org/10.1063/1.4933297

150. Ziaee, F., Rudenko, A., Rolles, D., Savelyev, E., Boll, R., Manschwetus, B., Erk, N., Trippel, S., Wiese, J., Kuepper, J., Amini, K., Lee, J., Brouard, M., Brauße, F., Rouzee, A., Olshin, P., Mereshchenko, A., Lahl, J., Johnsson, P., Simon, M., Marchenko, T., Holland, D., Underwood, J.: Probing ultrafast nuclear dynamics in halomethanes by time-resolved electron and ion imaging. In: APS Division of Atomic and Molecular Physics Meeting (2016)

151. Ablikim, U., Bomme, C., Savelyev, E., Xiong, H., Kushawaha, R., Boll, R., Amini, K., Osipov, T., Kilcoyne, D., Rudenko, A., Berrah, N., Rolles, D.: Isomer-dependent fragmentation dynamics of inner-shell photoionized difluoroiodobenzene. Phys. Chem. Chem. Phys. 19(21), 13419-13431 (2017). https://doi.org/10.1039/c7cp01379e

152. Allum, F., Burt, M., Amini, K., Boll, R., Köckert, H., Olshin, P.K., Bari, S., Bomme, C., Brauße, F., de Miranda, B.C., Düsterer, S., Erk, B., Géléoc, M., Geneaux, R., Gentleman, A.S., Goldsztejn, G., Guillemin, R., Holland, D.M.P., Ismail, I., Johnsson, P., Journel, L., Küpper, J., Lahl, J., Lee, J.W.L., Maclot, S., Mackenzie, S.R., Manschwetus, B., Mereshchenko, A.S., Mason, R., Palaudoux, J., Piancastelli, M.N., Penent, F., Rompotis, D., Rouzée, A., Ruchon, T., Rudenko, A., Savelyev, E., Simon, M., Schirmel, N., Stapelfeldt, H., Techert, S., Travnikova, O., Trippel, S., Underwood, J.G., Vallance, C., Wiese, J., Ziaee, F., Brouard, M., Marchenko, T., Rolles, D.: Coulomb explosion imaging of $\mathrm{CH} 3 \mathrm{i}$ and $\mathrm{CH} 2$ cli photodissociation dynamics. J. Chem. Phys. 149(20), 204,313 (2018). https://doi.org/10.1063/1.5041381

153. Amini, K., Boll, R., Lauer, A., Burt, M., Lee, J., Christensen, L., Brauße, F., Mullins, T., Savelyev, E., Ablikim, U., Berrah, N., Bomme, C., Düsterer, S., Erk, B., Höppner, H., Johnsson, P., Kierspel, T., Krecinic, F., Küpper, J., Müller, M., Müller, E., Redlin, H., Rouzée, 
A., Schirmel, N., Thøgersen, J., Techert, S., Toleikis, S., Treusch, R., Trippel, S., Ulmer, A., Wiese, J., Vallance, C., Rudenko, A., Stapelfeldt, H., Brouard, M., Rolles, D.: Alignment, orientation, and coulomb explosion of difluoroiodobenzene studied with the pixel imaging mass spectrometry (PImMS) camera. J. Chem. Phys 147(1), 013,933 (2017). https://doi.org/ $10.1063 / 1.4982220$

154. Amini, K., Savelyev, E., Brauße, F., Berrah, N., Bomme, C., Brouard, M., Burt, M., Christensen, L., Düsterer, S., Erk, B., Höppner, H., Kierspel, T., Krecinic, F., Lauer, A., Lee, J.W.L., Müller, M., Müller, E., Mullins, T., Redlin, H., Schirmel, N., Thøgersen, J., Techert, S., Toleikis, S., Treusch, R., Trippel, S., Ulmer, A., Vallance, C., Wiese, J., Johnsson, P., Küpper, J., Rudenko, A., Rouzée, A., Stapelfeldt, H., Rolles, D., Boll, R.: Photodissociation of aligned $\mathrm{CH} 3 \mathrm{i}$ and $\mathrm{c} 6 \mathrm{~h} 3 \mathrm{f} 2 \mathrm{i}$ molecules probed with time-resolved coulomb explosion imaging by site-selective extreme ultraviolet ionization. Struct. Dyn. 5(1), 014,301 (2018). https://doi. org/10.1063/1.4998648

155. Boll, R., Erk, B., Coffee, R., Trippel, S., Kierspel, T., Bomme, C., Bozek, J.D., Burkett, M., Carron, S., Ferguson, K.R., Foucar, L., Küpper, J., Marchenko, T., Miron, C., Patanen, M., Osipov, T., Schorb, S., Simon, M., Swiggers, M., Techert, S., Ueda, K., Bostedt, C., Rolles, D., Rudenko, A.: Charge transfer in dissociating iodomethane and fluoromethane molecules ionized by intense femtosecond X-ray pulses. Struct. Dyn. 3(4), 043,207 (2016). https://doi. org/10.1063/1.4944344

156. Boll, R., Rouzée, A., Adolph, M., Anielski, D., Aquila, A., Bari, S., Bomme, C., Bostedt, C., Bozek, J.D., Chapman, H.N., Christensen, L., Coffee, R., Coppola, N., De, S., Decleva, P., Epp, S.W., Erk, B., Filsinger, F., Foucar, L., Gorkhover, T., Gumprecht, L., Hömke, A., Holmegaard, L., Johnsson, P., Kienitz, J.S., Kierspel, T., Krasniqi, F., Kühnel, K.U., Maurer, J., Messerschmidt, M., Moshammer, R., Müller, N.L.M., Rudek, B., Savelyev, E., Schlichting, I., Schmidt, C., Scholz, F., Schorb, S., Schulz, J., Seltmann, J., Stener, M., Stern, S., Techert, S., Thøgersen, J., Trippel, S., Viefhaus, J., Vrakking, M., Stapelfeldt, H., Küpper, J., Ullrich, J., Rudenko, A., Rolles, D.: Imaging molecular structure through femtosecond photoelectron diffraction on aligned and oriented gas-phase molecules. Faraday Discuss. 171, 57-80 (2014). https://doi.org/10.1039/c4fd00037d

157. Brauße, F., Goldsztejn, G., Amini, K., Boll, R., Bari, S., Bomme, C., Brouard, M., Burt, M., de Miranda, B.C., Düsterer, S., Erk, B., Géléoc, M., Geneaux, R., Gentleman, A.S., Guillemin, R., Ismail, I., Johnsson, P., Journel, L., Kierspel, T., Köckert, H., Küpper, J., Lablanquie, P., Lahl, J., Lee, J.W.L., Mackenzie, S.R., Maclot, S., Manschwetus, B., Mereshchenko, A.S., Mullins, T., Olshin, P.K., Palaudoux, J., Patchkovskii, S., Penent, F., Piancastelli, M.N., Rompotis, D., Ruchon, T., Rudenko, A., Savelyev, E., Schirmel, N., Techert, S., Travnikova, O., Trippel, S., Underwood, J.G., Vallance, C., Wiese, J., Simon, M., Holland, D.M.P., Marchenko, T., Rouzée, A., Rolles, D.: Time-resolved inner-shell photoelectron spectroscopy: From a bound molecule to an isolated atom. Phys. Rev. A 97(4) (2018). https://doi.org/10. 1103/physreva.97.043429

158. Burt, M., Boll, R., Lee, J.W.L., Amini, K., Gentleman, A.S., Klöckert, H., Mackenzie, S.R., Vallance, C., Bari, S., Bomme, C., Dachraoui, H., Düsterer, S., Erk, B., Manschwetus, B., Müller, E., Rompotis, D., Savelyev, E., Schirmel, N., Techert, S., Treusch, R., Küpper, J., Trippel, S., Wiese, J., Stapelfeldt, H., de Miranda, B.C., Guillemin, R., Ismail, I., Journel, L., Marchenko, T., Palaudoux, J., Penent, F., Piancastelli, M.N., Simon, M., Travnikova, O., Brauße, F., Goldsztejn, G., Rouzee, A., Geleoc, M., Geneaux, R., Ruchon, T., Underwood, J., Holland, D.M.P., Mereshchenko, A.S., Olshin, P.K., Johnsson, P., Maclot, S., Lahl, J., Rudenko, A., Ziaee, F., Brouard, M., Rolles, D.: Coulomb-explosion imaging of concurrent CH2bri photodissociation dynamics. Phys. Rev. A 96(4) (2017). https://doi.org/10.1103/ physreva.96.043415

159. Erk, B., Boll, R., Trippel, S., Anielski, D., Foucar, L., Rudek, B., Epp, S.W., Coffee, R., Carron, S., Schorb, S., Ferguson, K.R., Swiggers, M., Bozek, J.D., Simon, M., Marchenko, T., Kupper, J., Schlichting, I., Ullrich, J., Bostedt, C., Rolles, D., Rudenko, A.: Imaging charge transfer in iodomethane upon X-ray photoabsorption. Science 345(6194), 288-291 (2014). https://doi.org/10.1126/science.1253607 
160. Erk, B., Rolles, D., Foucar, L., Rudek, B., Epp, S.W., Cryle, M., Bostedt, C., Schorb, S., Bozek, J., Rouzee, A., Hundertmark, A., Marchenko, T., Simon, M., Filsinger, F., Christensen, L., De, S., Trippel, S., Küpper, J., Stapelfeldt, H., Wada, S., Ueda, K., Swiggers, M., Messerschmidt, M., Schröter, C.D., Moshammer, R., Schlichting, I., Ullrich, J., Rudenko, A.: Ultrafast charge rearrangement and nuclear dynamics upon inner-shell multiple ionization of small polyatomic molecules. Phys. Rev. Lett. 110(5) (2013). https://doi.org/10.1103/physrevlett.110.053003

161. Müller, A., Borovik, A., Bari, S., Buhr, T., Holste, K., Martins, M., Perry-Saßmannshausen, A., Phaneuf, R., Reinwardt, S., Ricz, S., Schubert, K., Schippers, S.: Near-k-edge double and triple detachment of the f-negative ion: Observation of direct two-electron ejection by a single photon. Phys. Rev. Lett. 120(13) (2018). https://doi.org/10.1103/physrevlett.120.133202

162. Rolles, D., Boll, R., Adolph, M., Aquila, A., Bostedt, C., Bozek, J.D., Chapman, H.N., Coffee, R., Coppola, N., Decleva, P., Delmas, T., Epp, S.W., Erk, B., Filsinger, F., Foucar, L., Gumprecht, L., Hömke, A., Gorkhover, T., Holmegaard, L., Johnsson, P., Kaiser, C., Krasniqi, F., Kühnel, K.U., Maurer, J., Messerschmidt, M., Moshammer, R., Quevedo, W., Rajkovic, I., Rouzée, A., Rudek, B., Schlichting, I., Schmidt, C., Schorb, S., Schröter, C.D., Schulz, J., Stapelfeldt, H., Stener, M., Stern, S., Techert, S., Thøgersen, J., Vrakking, M.J.J., Rudenko, A., Küpper, J., Ullrich, J.: Femtosecond X-ray photoelectron diffraction on gas-phase dibromobenzene molecules. J. Phys. B: Atom. Mol. Opt. Phys. 47(12), 124,035 (2014). https:// doi.org/10.1088/0953-4075/47/12/124035

163. Rudenko, A., Inhester, L., Hanasaki, K., Li, X., Robatjazi, S.J., Erk, B., Boll, R., Toyota, K., Hao, Y., Vendrell, O., Bomme, C., Savelyev, E., Rudek, B., Foucar, L., Southworth, S.H., Lehmann, C.S., Kraessig, B., Marchenko, T., Simon, M., Ueda, K., Ferguson, K.R., Bucher, M., Gorkhover, T., Carron, S., Alonso-Mori, R., Koglin, J.E., Correa, J., Williams, G.J., Boutet, S., Young, L., Bostedt, C., Son, S.K., Santra, R., Rolles, D.: Femtosecond response of polyatomic molecules to ultra-intense hard X-ray. Nature 546(7656), 129-132 (2017). https:// doi.org/10.1038/nature22373

Open Access This chapter is licensed under the terms of the Creative Commons Attribution 4.0 International License (http://creativecommons.org/licenses/by/4.0/), which permits use, sharing, adaptation, distribution and reproduction in any medium or format, as long as you give appropriate credit to the original author(s) and the source, provide a link to the Creative Commons license and indicate if changes were made.

The images or other third party material in this chapter are included in the chapter's Creative Commons license, unless indicated otherwise in a credit line to the material. If material is not included in the chapter's Creative Commons license and your intended use is not permitted by statutory regulation or exceeds the permitted use, you will need to obtain permission directly from the copyright holder.

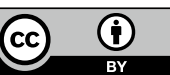

